\title{
NEW FORMS OF INSTRUMENTS FOR SHOWING THE PRESENCE AND AMOUNT OF COMBUSTIBLE GAS IN THE AIR
}

By E. R. Weaver and E. E. Weibel

\section{CONTENTS}

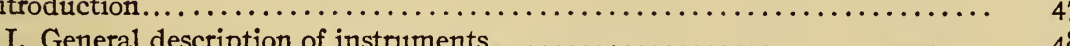

I. Principles of operation of new devices .

2. Compensated-bridge indicator $\ldots \ldots \ldots \ldots \ldots \ldots \ldots \ldots \ldots \ldots \ldots \ldots \ldots, 49$

3. Glowing-wire indicator........................ 5 I

4. Bimetallic detector............................... $5^{2}$

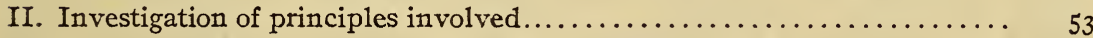

I. Combustion at the surface of a heated wire................ 53

(a) Purpose and methods of experiments............... 53

(b) Results of experiments........................ $5_{58}$

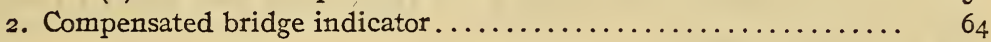

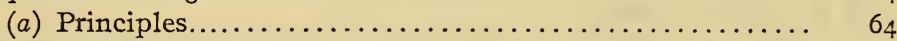

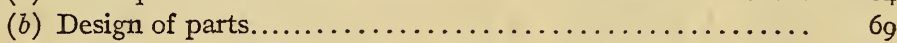

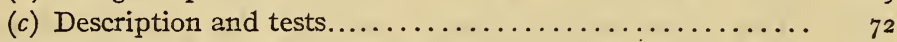

3. Glowing-wire indicator............................... 77

4. Bimetallic detector................................ 78

III. Specifications for the construction and calibration of instruments...... $8 \mathrm{I}$

r. Compensated bridge indicator......................... $8 \mathrm{I}$

(a) Construction of apparatus................. $8 \mathrm{I}$

2. Glowing-wire indicator................................ 88

3. Bimetallic detector.................................... 89

\section{INTRODUCTION}

The detection and automatic indication of the presence of combustible gases in the air is a problem of great importance in many industries both for controlling certain processes and for safeguarding life and property wherever there is danger of fire or explosions due to the presence of such mixtures. In the spring of I916, an investigation of some of the forms of gas detectors in use was begun by the Bureau of Standards.

None of the existing forms of apparatus was found suitable for all purposes, and the investigation has led to the design of several new forms which are more reliable than the old ones or better adapted to certain specific uses. These new forms of ap- 
paratus are the subject of the present paper. The experimental work described was completed about April I, I9I7, but for various reasons it has not been published until the present time.

A paper describing the older forms of detectors, at least in principle, and some of the experimental work done upon them, is in preparation.

After the work on the compensated bridge indicator was completed a United States patent was granted to Messrs. Philip and Steele ${ }^{1}$ covering many of the features of this type of instrument as developed at the Bureau of Standards. The date of application for their patent shows that Messrs. Philip and Steele's work far antedates our own. The forms of the two instruments, the conditions under which they were designed to be used, and the methods of using them are so different, however, that a description of the Bureau of Standards form of instrument seems well worth while. In addition, the large amount of experimental work relating to gaseous combustion at the surface of heated wires is of general application to any instrument depending for its action upon this phenomenon.

For convenience the report on this work has been divided into the following parts:

Section I contains a brief description of the new devices, the principles upon which they operate, the results of tests showing their accuracy and reliability, and a brief discussion of their application.

Section II is a detailed account of the theory involved in the design of the instruments and of the experimental work concerned with the features of design, together with a description of the tests to which the completed instruments have been subjected.

Section III contains drawings and specifications for the construction and installation of the instruments and accessory apparatus.

\section{GENERAL DESCRIPTION OF INSTRUMENTS}

\section{PRINCIPLES OF OPERATION OF NEW DEVICES}

All of the new devices described in this paper depend upon the combustion at the surface of an electrically heated platinum wire of the gas contained in the surrounding atmosphere. This surface combustion takes place at a temperature much below the normal ignition temperature of the gas in air or at the surface of another 
material which does not exert a catalytic effect. The resulting rise in temperature of the wire depends upon the quantity of the combustible gas which is present. The measurement of temperature rise is made in various ways, each of which is better suited to certain particular purposes than is any of the others. For some purposes an indicator is required-i. e., an instrument which will indicate, either continuously or when desired, the amount of the combustible gas present. For other purposes only a detector is required-i. e., an instrument which sounds an alarm or otherwise shows the presence of a dangerous amount of the combustible gas. The following devices which have been developed are suited to various uses:

I. The "compensated bridge indicator," depending for its operation upon the change in electrical resistance of the wire, gives a continuous indication of the amount of combustible gas at the point at which the resistance element, called the "detector bridge," is placed. When the percentage of gas reaches a predetermined limit, a circuit is closed, actuating an alarm or other protective device.

2. The "glowing-wire indicator" is a portable device with which an observer may quickly determine the amount of combustible gas at any accessible place. This is done by adjusting the current through an active wire to such a value that the wire just shows a visible glow. The current required decreases with increase in the amount of gas present.

3. The "bimetallic detector" is an automatic device in which the heat of combustion of the gas at the surface of the wire causes the bending of an adjacent bimetallic strip, which in turn closes an alarm circuit.

\section{COMPENSATED BRIDGE INDICATOR}

Description.-The resistance element or detector bridge of the compensated bridge indicator consists of a balanced Wheatstone bridge made up of four platinum wires, two of which, on opposite sides of the bridge, are rendered inactive by a thin coating of some substance which does not readily cause surface combustion. The bridge wires are heated by an electrical current to a temperature high enough to cause combustion of the gas at the surface of the uncoated or "active" wires. When no combustible gas is present, the active and inactive wires are about equally affected by changes of electrical current, room temperature, and air currents. Consequently, the bridge remains balanced in spite of 
changes in surrouhding conditions; but in the presence of a combustible gas combustion takes place at the surface of the active wires, increasing their temperature and resistance, while no change occurs in the inactive wires. Consequently, the bridge becomes unbalanced by an amount depending upon the quantity of combustible gas present. A voltmeter with scale graduated to show the percentage of the combustible gas to be indicated (e. g., hydrogen in electrolytic oxygen or carbon monoxide about gas producers) is connected across the bridge and serves to show at all times the percentage of gas present. A contact-making attachment causes an alarm to ring when the amount of gas reaches the limit for which the contact has been set. A diagram of a compensated bridge indicator is given in Fig. I7.

Tests.-Several instruments of this type have been made and tested at the Bureau of Standards. The indicators show smaller changes in hydrogen concentration than can be detected by ordinary volumetric analysis, but their operation over a long period of time usually results in a change of balance which makes it necessary to rebalance. The absolute accuracy of the readings can not, of course, be greater at any time than the volumetric analyses by which the instruments were calibrated. The tests upon one instrument, which was in constant use for several months in a battery compartment, show that the instrument is capable of giving good results over a considerable period of time if operated under the most favorable conditions. These conditions include the maintenance of a constant current, freedom from excessive vibration, and the requirement that the instrument be not exposed to a high concentration of combustible gas for a very long period of time. All of these requirements depend upon the low elastic limit of platinum at high temperatures and the consequent slow stretching of the wires, even under their own weight.

The suitability of the instrument for indicating methane is doubtful on account of the high temperature required. For a short period of time, it will give reliable indications of this gas; but it is improbable that permanent changes in the wires at so high a temperature could be long avoided.

Application.-The device is suited to the continuous indication of the presence of hydrogen, carbon monoxide, illuminating gas, methane, and the vapors of some combustible liquids in air. It is especially suitable for use in determining the com position of gas in inaccessible places and for indicating at some central station the condition of the atmosphere in all parts of an industrial plant. 
Merits of the Compensated Bridge Indicator.-The experience with the apparatus up to the present time apparently fully justifies the following statements as to the merits of the compensated bridge indicator:

I. The apparatus is of simple construction, readily made up from ordinary materials by any competent instrument maker.

2. The detector bridge can be made small, and, since it requires no attention, can be located at any desired point even though somewhat inaccessible.

3. The indicating instrument can be located at a distance from the resistance element and the alarm, if desired, at a distance from either.

4. The apparatus requires little attention in operation.

5. No supplies are required except direct current of the voltage ordinarily used on lighting circuits. The apparatus is readily adapted for use on a circuit of any voltage above 5 volts.

6. The usual variation of the voltage of the electrical supply does not affect materially the operation of the instrument unless excessively high or low voltages are long continued.

7. The apparatus, when once properly calibrated, will indicate changes of concentration of hydrogen smaller than can be detected by the methods of gas analysis commonly used in commercial practice.

8. The apparatus operates an alarm at any desired percentage of combustible gas.

9. The indications of the apparatus are not affected by changes in temperature at the point of location of the detector bridge.

Io. The apparatus responds promptly to changes in the amount of combustible gas present, for the time lag is not more than Io seconds for a properly constructed instrument.

II. The most important and delicate parts of the apparatus are made of some of the materials most resistant to chemical action, namely, platinum and glass.

I2. The initial cost of construction of the apparatus is not great, the most expensive part being a voltmeter of ordinary commercial form.

\section{GLOWING-WIRE INDICATOR}

The glowing-wire indicator consists of two short lengths of fine platinum wire, the currents through which are supplied by a dry battery and controlled by two small rheostats. A wiring diagram is shown in Fig. $2 \mathrm{I}$. The whole is arranged in a convenient 
form for carrying in the hand or the pocket. One wire is active; the other inactive. By adjusting the two rheostats the two wires may be made to glow with the same intensity. One rheostat determines the ratio of the currents in the wires which changes with percentage of gas present. This rheostat can therefore be graduated to read percentage directly. The other rheostat serves to regulate the total current through both wires. This device is practically independent of the illumination at the place of use and entirely independent of the voltage of the battery used.

The glowing-wire indicator is, of course, designed for the purpose of directly observing the atmospheric condition at a point at which no permanent detector is located. It should be of value in looking for leaks in gas mains and examining spaces, such as coal bunkers, or gas-making machinery opened for repairs in which the presence of a dangerous amount of combustible gas is suspected.

The apparatus is considerably more complicated and somewhat more expensive than the detecting bridge of the bridge indicator, but no additional electrical instrument or alarm is required, and the apparatus as a whole should not cost more than one-half as much as a complete bridge indicator.

\section{BIMETALLIC DETECTOR}

The bimetallic detector, which is intended only to actuate an alarm or other mechanism when the amount of combustible gas in the atmosphere reaches the limit for which the device is set, is a simple and inexpensive instrument, the principle of which was first used by Alderson and Holmes, ${ }^{2}$ who specify a detector substantially like the one designed at this Bureau. The Bureau instrument consists of two bimetallic strips with one end of each rigidly fixed to an insulating support. A millimeter or two below the strips are stretched platinum wires, one active, the other inactive, which serve to heat the bimetallic strips. When equally heated these strips bend equally, but when unequally heated they indicate by a relative movement of their free ends the difference in temperature.

The platinum wires are connected in series, to any convenient. source of electrical current, direct or alternating. The free ends of the bimetallic strips bear contact points which, when the strips come together, short circuit the platinum wires through an alarm, as is shown by the wiring diagram in Fig. I6. In an atmosphere 
free from combustible gas the two bimetallic strips are equally heated by the currents through the platinum wires and bend alike whatever the amount of heat from the electrical current or other source which affects the two strips alike. But in the presence of a combustible gas, combustion at the surface of the active wire causes the adjacent strip to be heated to a higher temperature. This results in a movement of this strip which closes the alarm circuit if gas is present in excess of the predetermined quantity for which the apparatus is set. One of the contacts is adjustable, permitting the instrument to be set for various percentages of combustible gas.

The device has been tried out and found to operate satisfactorily. It may be made very sensitive to the presence of a combustible gas. The instrument tried out at the Bureau could be readily adjusted to sound the alarm at less than o.I per cent of hydrogen.

The bimetallic detector is especially adapted for use in any place in which a sensitive device for alarm only is desired. It can be located wherever the detector bridge of a bridge indicator could be placed, and its low cost makes it available for use in many positions in which the cost of installing a bridge indicator would not be justified. The instrument may be made small, the one constructed at this Bureau having the dimensions 3 by 5 by ro centimeters, equal to about I I/4 inches by 2 inches by 4 inches. It is even less subject than the bridge indicator to drafts, changes of current, and other possible disturbing influences. The fact that it will use alternating as well as direct current makes the instrument available for use on any power supply.

\section{INVESTIGATION OF PRINCIPLES INVOLVED}

\section{COMBUSTION AT THE SURFACE OF A HEATED WIRE}

(a) PURPOSE AND METHODS OF EXPERIMENTS

In order to design intelligently any of the instruments described in the first part of this paper, it was necessary to determine with some accuracy the most suitable materials for the active and inactive wires; the temperature required to cause combustion at the surface of the active wire; the relations between the resistance, temperature, current, diameter, length, and arrangement of wires in the apparatus; and the amount of heat produced by combustion in atmospheres containing various amounts of combustible gas with each arrangement.

$86062^{\circ}-19-2$ 
Methods of Study.-Owing to the large number and variety of experiments made upon combustion at the surface of heated wires, it would be confusing to endeavor to present all the methods employed independently of a discussion of the immediate objects of the experiments and the results obtained. The basic experiments should be, however, briefly described before giving in detail the results obtained. Wires of various materials and sizes were heated electrically in air and in various gas mixtures. In each experiment the heating current, $I$, and the resistance, $R$, of the wires were measured. The mean temperatures, $t$, of the platinum

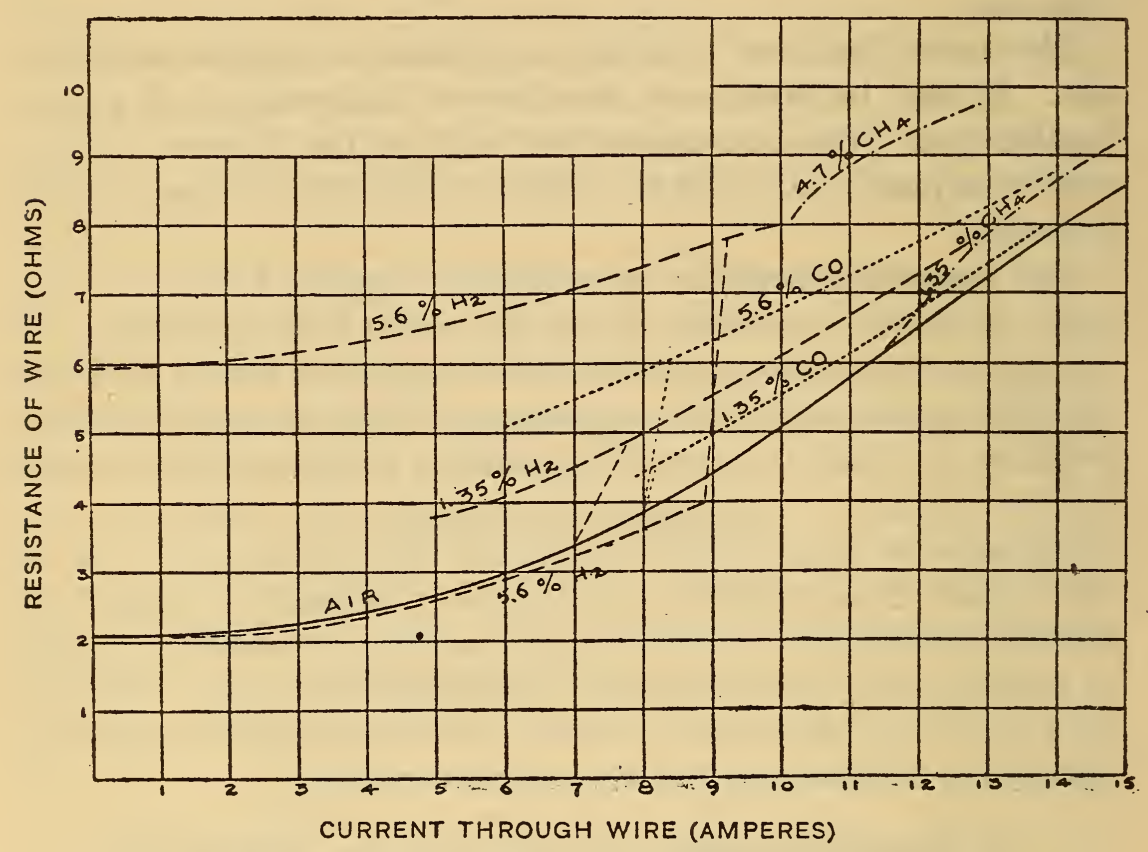

FIG. I.-Representative observations of combustion at the surface of a heated wire

wires were determined from their resistance by using the known relation between temperature and resistance $R=R_{0}\left(\mathrm{I}+A t-B t^{2}\right)$. In the few cases when it was necessary to know the temperatures of wires of other metals, these were determined approximately by assuming the temperature equal to that of a platinum wire of the same diameter heated by the same amount of power. The rate of dissipation of energy from the wire was, of course, equal to the sum of the input of electrical power, $R I^{2}$, and the rate of production of heat by combustion, called $H$. If we assume that the rate of dissipation of energy from the wire was independent of small changes in the composition of the surrounding atmosphere, then 
the difference in electrical power input required to maintain the wire at the temperature $t$ with and without combustion taking place is equal to the power input from combustion, $H$.

A group of characteristic curves representing the observation upon a particular wire is given in Fig. I, while Table I presents the numerical data for one gas mixture, together with some of the quantities of interest which are computed from the observation. The discontinuity of the curves in Fig. I is caused by the fact that the wire may be heated by a fairly large current without combustion taking place, but when combustion is once started it will continue in some cases even when the current is reduced to zero. The application of the results of these experiments to the problems of design will appear when the results are described in detail.

TABLE 1.-Representative Data on Combustion of Carbon Monoxide at the Surface of a Platinum Wire $0.097 \mathrm{~mm}$ in Diameter and $14 \mathrm{~cm}$ long (amount of carbon monoxide in air entering bottle 5.6 per cent)

\begin{tabular}{c|c|c|c|c|c}
\hline $\begin{array}{c}\text { Current ob- } \\
\text { served, } I\end{array}$ & $\begin{array}{c}\text { Resistance ob- } \\
\text { served, } R\end{array}$ & $\begin{array}{c}\text { Electrical } \\
\text { power, } R I^{2}\end{array}$ & $\begin{array}{c}\text { Temperature, } \\
t\end{array}$ & $\begin{array}{c}\text { Heat loss in } \\
\text { air, } L\end{array}$ & $\begin{array}{c}\text { Power from } \\
\text { combustion, } \\
L_{-} I^{2}\end{array}$ \\
\hline Amperes & Ohms & Watts & ${ }^{\circ}$ C & Watts & Watts \\
0.5 & 2.67 & 0.67 & 115 & 0.67 & 0.00 \\
0.6 & 5.09 & 1.83 & 526 & 5.09 & 3.26 \\
0.7 & 5.47 & 2.68 & 596 & 6.07 & 3.39 \\
0.8 & 5.88 & 3.76 & 669 & 7.20 & 3.44 \\
0.9 & 6.31 & 5.11 & 750 & 8.60 & 3.49 \\
1.0 & 6.78 & 6.78 & 840 & 10.20 & 3.42 \\
1.1 & 7.28 & 8.22 & 950 & 12.19 & 3.37 \\
1.2 & 7.79 & 11.22 & 1065 & 15.76 & 4.54 \\
1.3 & 8.28 & 14.00 & 1182 & 17.58 & 3.58 \\
1.4 & 8.79 & 17.23 & 1313 & 21.04 & 3.81 \\
\hline
\end{tabular}

Apparatus Used.-The apparatus used in the experiments just outlined is shown diagrammatically in Fig. 2. The test wire was placed in a bottle $28 \mathrm{~cm}$ in diameter and $40 \mathrm{~cm}$ high. It was connected by copper leads about $4 \mathrm{~mm}$ in diameter to the standard resistances connected to form a Wheatstone bridge as shown. A steady stream of gas of constant composition was passed through the test chamber. A gas mixture of constant composition was obtained by gearing together two calibrated wet meters, one of which measured the air, the other the combustible gas, and passing the mixture from the meters into a mixing bottle to reduce fluctuations in composition. The composition of the mixture entering the test bottle was checked from time to time by gas analysis. When suitable precautions were used, this method was found quite 
satisfactory, the composition of the mixture remaining very constant and agreeing well with the values calculated from the meter calibrations. In the final experiments, samples of gas were also taken through a capillary tube from a point very near the wires. Gas analyses were made by an ordinary combustion method, using a roo cc burette graduated to o.I cc and a Levy combustion capillary of fused quartz containing a glowing platinum wire.

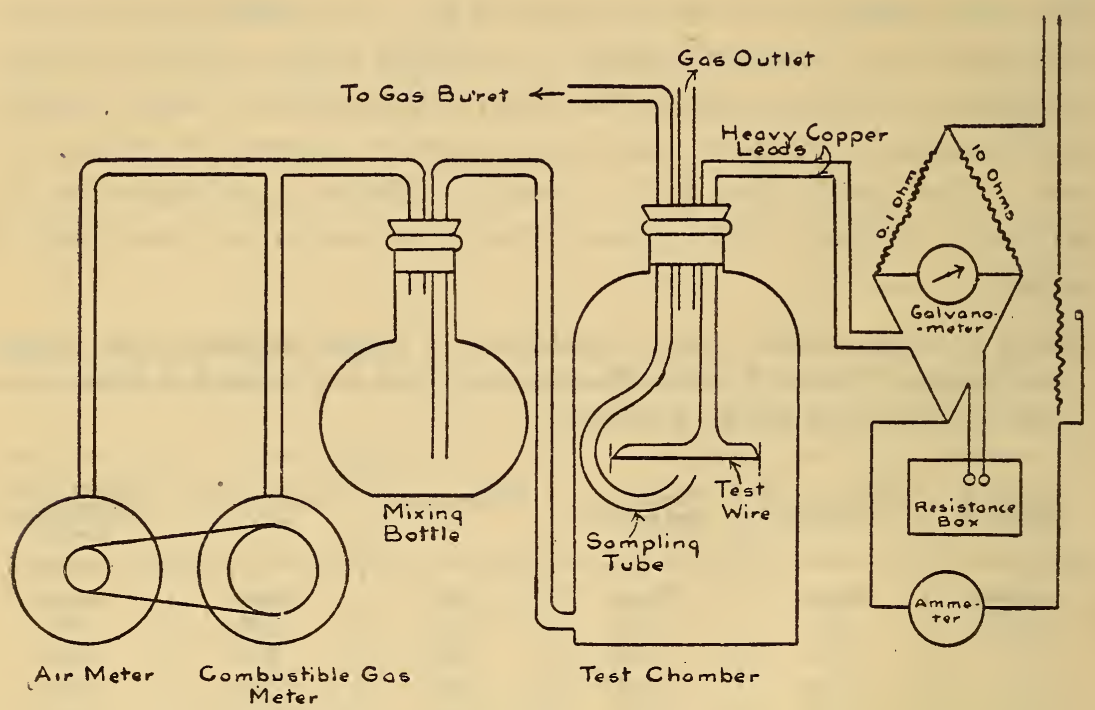

FIG. 2.-Apparatus for determining combustion at the surface of heated wires

Wires Used in Investigation.-Table 2 gives the sizes and some of the constants of the wires used in this investigation.

TABLE 2

\begin{tabular}{|c|c|c|c|c|c|c|}
\hline \multirow{2}{*}{ Designation } & \multirow{2}{*}{ Material } & \multirow{2}{*}{$\begin{array}{c}\text { Diameter } \\
\text { in } \\
\text { millimeters }\end{array}$} & \multirow{2}{*}{$\begin{array}{l}\text { Resistivity } \\
\text { at } 0^{\circ} \mathrm{C} \text {, } \\
\text { microhm } \\
\text { per cm }{ }^{3}\end{array}$} & \multicolumn{2}{|c|}{ Temperature coefficients } & \multirow{2}{*}{ Remarks } \\
\hline & & & & A & $\mathbf{B}$ & \\
\hline A............. & Platinum......... & 0.012 & 11.6 & 0.0036 & 0.00000058 & Wollaston wire. \\
\hline B........... & .....do........... & .053 & 13.8 & .00278 & .00000058 & Commercial wire. \\
\hline C... & .....do..... & .097 & 10.35 & .00367 & .00000058 & \\
\hline \multirow[t]{5}{*}{ 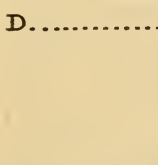 } & .....do............. & .226 & 9.8 & .00382 & .00000058 & \\
\hline & Palladium. . & .226 & 11.1 & & & \\
\hline & Gold............. & .226 & 2.15 & & & \\
\hline & Silver........... & .226 & 1.52 & & & \\
\hline & Nickel............ & .226 & 10.0 & & & \\
\hline
\end{tabular}

Accuracy of Observations. - The accuracy of the standard resistances and the sensitiveness of the galvanometer used were greater. than the general accuracy demanded in the investigation. The 
resistances of the leads were measured and taken into account whenever of any importance, but in most of the experiments this correction was entirely negligible. The currents used were never large enough to cause appreciable errors due to the heating of the measuring resistances. The only appreciable source of error in the electrical measurements was in the observation of the current. Several instruments of standard make and appropriate range were used for this purpose in the different experiments, and corrections were always made for the portion of the current, seldom more than I per cent, which passed through the ammeter but not through the test wire. When different ammeters were used for experiments made under the same conditions, the corrected results were always concordant.

Without doubt the most important source of error was that involved in determining the amount of combustible gas present. It was the object of the experiments to determine how much power from combustion was available for the detection of the combustible gases. It would have been desirable to reproduce the conditions which would exist if a heated wire were exposed to the atmosphere of a large chamber containing a uniform amount of combustible gas and free from air currents other than those caused by the hot wire. However, because a considerable amount of the combustible gas is burned out of a space the size of the bottle used, the composition of the gas in the bottle is never the same as that of the gas at the inlet. Passing gas into the bottle at an accelerated rate makes the composition of the gas throughout the bottle more uniform, but causes strong air currents which may affect the condition of the wire to a considerable extent. Analyzing a sample of gas from a point near the wire does not entirely solve the problem, since it is uncertain to what distance the operation of the wire in an open room would affect the composition of the atmosphere.

Another approximation is involved in the calculation of the temperature of the wire, the heat from combustion per unit length, etc., from the average resistance per unit length. There is always a cooling effect due to conduction through the leads. This source of error has, in most cases, been neglected, on account of its small magnitude, the difficulty of correcting for it, and because it occurs to about the same extent in the complete instruments as in the test wires, and failure to consider it has little or no effect upon the design of the instruments. 
(b) RESULTS OF EXPERIMENTS

Temperature Coefficient of Resistance.-Before proceeding to a detailed study of combustion at the surface of a wire, it is first necessary to know the relation between resistance and temperature for the wires used. The temperature coefficient of resistance was determined over the interval from o to $100^{\circ} \mathrm{C}$ for the wires used in all the more important experiments, and the resistancetemperature curve plotted to $\mathrm{I} 200^{\circ} \mathrm{C}$ using the formula $R=R_{0}$ $\left(\mathrm{I}+A t-B t^{2}\right)$, assuming a value of $B$ equal to that for pure plati-

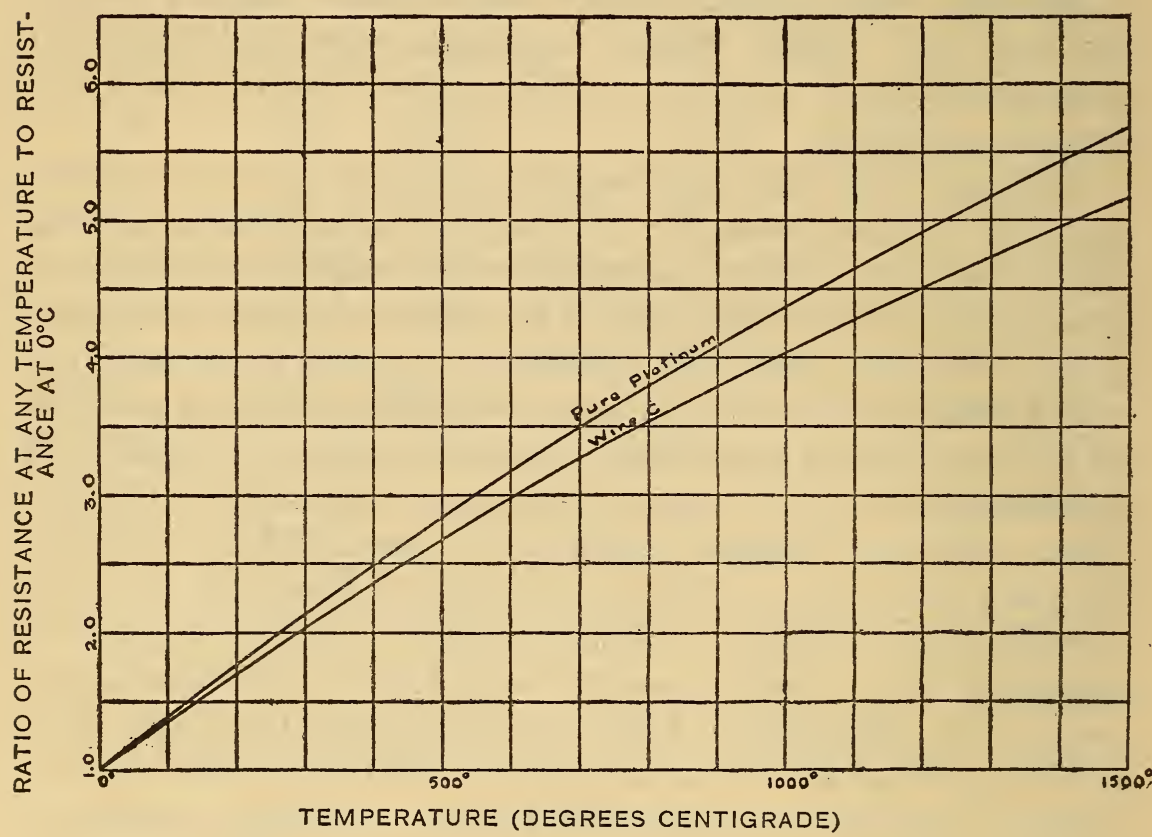

FIG. 3.-Temperature-rosistance curve for platinnm.

num. Above $1200^{\circ}$ the curve was continued as a straight line. ${ }^{3}$ The temperature-resistance curves for pure platinum and for wire $\mathrm{C}$, which was most used in these experiments, are given in Fig. 3.

Heat Loss from Wires in Air.-The loss of heat from wires in air has been made the object of study by numerous observers who have proposed formulas for expressing the observed values. The most generally accepted formulas are those due to Langmuir ${ }^{4}$ and to Lorenz. ${ }^{5}$

In Fig. 4 are plotted the observed average heat loss per centimeter from $3.8, \mathrm{I} 4$, and $3 \mathrm{I} \mathrm{cm}$ lengths of wire $\mathrm{C}$ and an $\mathrm{II} \mathrm{cm}$ length of wire $A$. As checks upon these observations the heat 
loss from the larger wire calculated from Lorenz's formula, and the heat loss for both wires calculated from Langmuir's formula are plotted. The constants in the Lorenz formula were calculated from the observed heat loss at $400^{\circ} \mathrm{C}$. In calculating for both curves the heat loss due to radiation, the values used for the emissivity of platinum at various temperatures were taken from Langmuir's paper.

The observed heat loss for the larger wire lies between the values calculated from the formulas of Lorenz and of Langmuir.

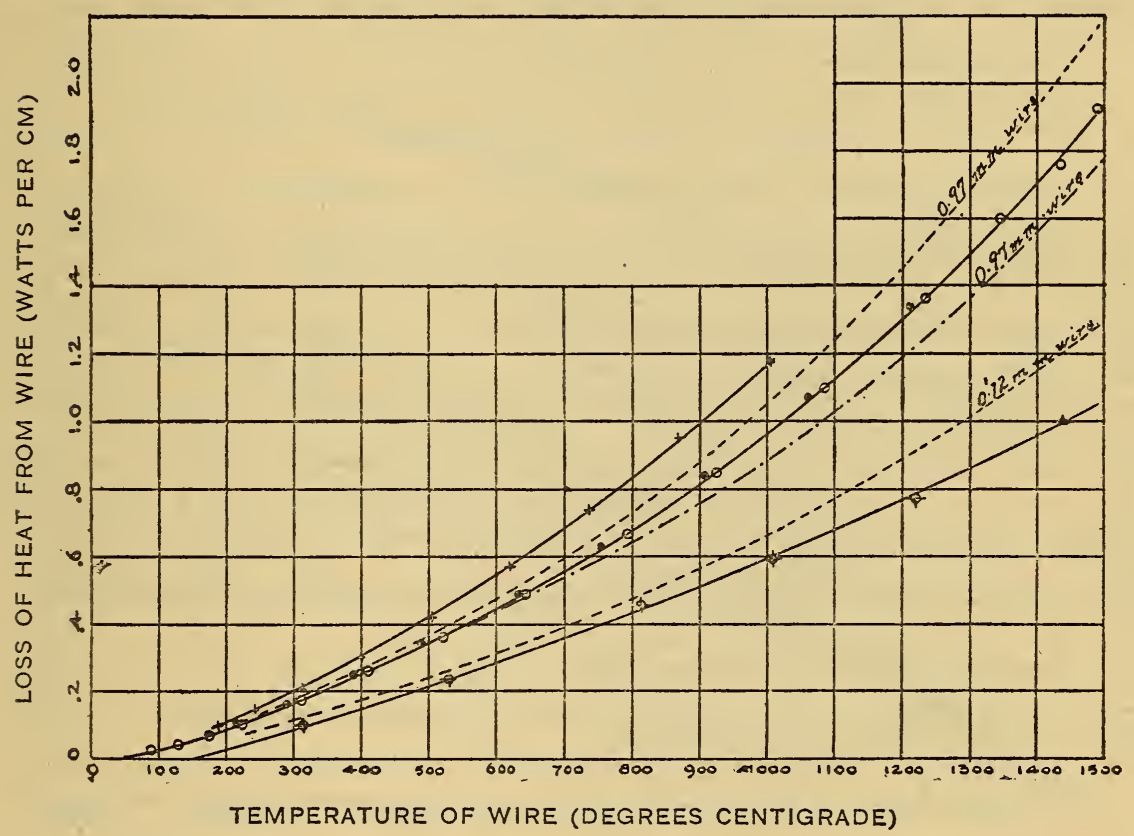

FIG. 4.-Loss of heat from wires in air

Curves in order from top represent: (I) Observed loss from $14 \mathrm{~cm}$ length of $0.097 \mathrm{~mm}$ wire; (2) loss from infinite length of same wire calculated from Langmuir's equation; $(3)$ observed loss from I4 and $3 \mathrm{I} \mathrm{cm}$ lengths of same wire; $(4)$ loss from infinite length of same wire calculated from Lorenz's equation; (5) loss from infinite length of $0.012 \mathrm{~mm}$ wire calculated from Langmuir's equation; (6) observed loss from 0.012 $\mathrm{mm}$ wire.

It is apparent that for reasonable lengths of wire the difference between the observed average heat loss at a given temperature and the true heat loss is negligible for our purposes.

The distribution of heat due to combustion is probably nearly the same as that due to the electrical current. If this is true, no serious error due to lead conduction is involved in the values for power from combustion per unit length.

Metal Used.-In order to determine what metals were most suitable for the detector wires, platinum, palladium, gold, silver, and nickel wires were heated in mixtures of air with amounts of 
hydrogen varying from a few tenths of a per cent up to and beyond the explosive limit. A few of the observations on wires 0.226 $\mathrm{mm}$ in diameter are plotted in Fig. 5. It was found that all the metals behave similarly until a temperature of about $175^{\circ} \mathrm{C}$ is reached. Above this temperature combustion takes place at the surface of both the platinum and palladium, and the amount of combustion increases at first very rapidly with rise of temperature and then becomes nearly constant. Since, when combustion begins, the rise of temperature due to combustion itself raises the temperature of the wire considerably, the resistance-

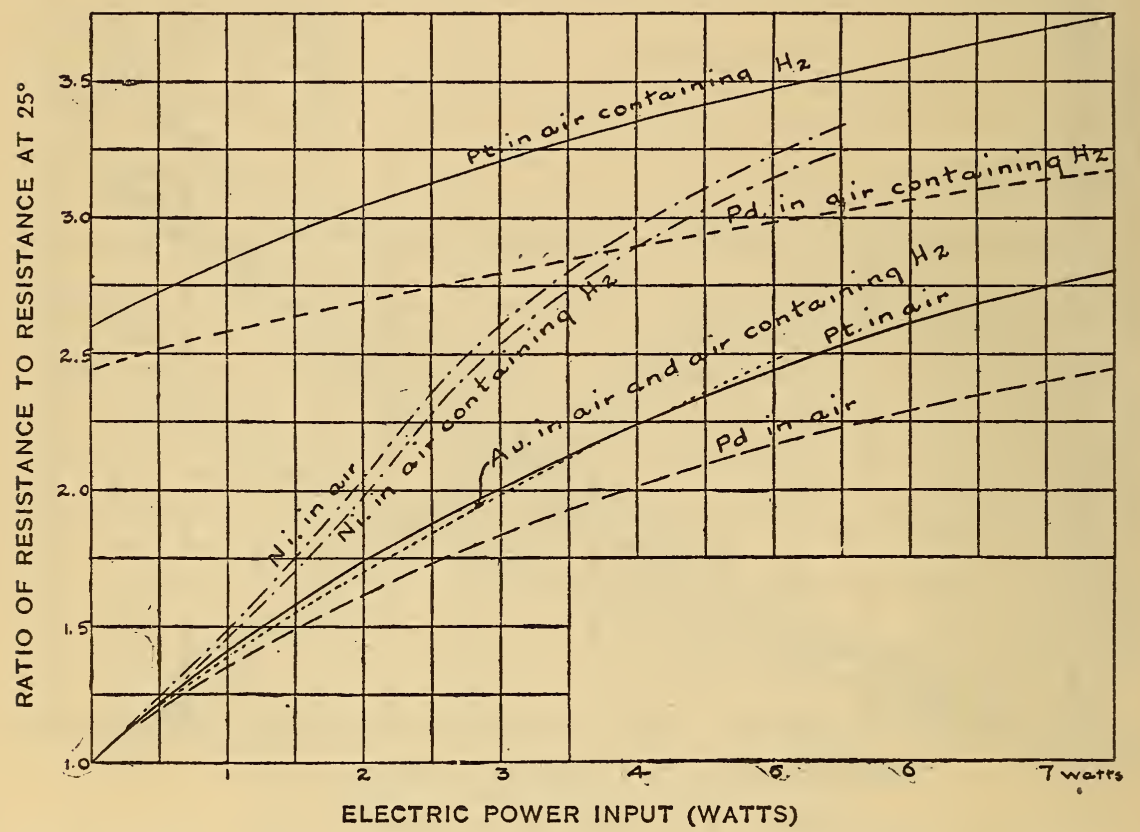

FIG. 5.-Change of resistance of heated wires of same size but of different metals in air and in air containing 5 per cent hydrogen

current curve shows a decided break when the temperature reaches a value such that the rate of increase of power from combustion becomes greater than the rate of increase of heat loss. This temperature is for convenience called the "ignition temperature," although it should be understood that some combustion takes place below this temperature and that combustion is not necessarily complete even at higher temperatures. In Fig. 5, the curves for platinum and palladium in air containing hydrogen represent the data obtained after heating to the ignition temperature. Gold, silver, and nickel show no such definite ignition temperature; indeed, the effect of the presence of hydro- 
gen is only to cool these metals until a temperature of at least six or seven hundred degrees is reached.

These experiments with various metals show that there is no inherent advantage in the use of palladium over platinum for the combustion even of hydrogen, and that none of the other metals tried can be used for active wires. On the other hand, platinum has several advantages over palladium; it has a higher temperature coefficient of resistance causing a greater increment of resistance for the same amount of combustion, it has a higher melting point and is therefore less likely to be accidentally burned out, it is much more resistant to chemical action, and it is somewhat easier to obtain commercially. Platinum has, therefore, been used exclusively for the apparatus recommended.

Ignition Temperatures. - The temperature to which a detector wire must be heated is determined by the so-called "ignition temperature" defined in the preceding section. It was, consequently, of considerable importance to determine the ignition temperature of platinum in the various gases. Direct observations for this purpose were made with three wires, samples $A, B$, and $\mathrm{C}$, which contained different amounts of impurity, as shown by their temperature coefficients given in Table 2 .

The Wollaston wire (sample A) was used immediately after dissolving the silver in nitric acid and without previous heating.

The method of observation was as follows: By very slowly increasing the current through the wire, it was gradually heated in an atmosphere containing the gas, the percentage of which was found to make no difference in the ignition temperature. The Wheatstone bridge was kept balanced at all times. As soon as the resistance of the wire began to increase without increase of current, the resistance reading was recorded and the corresponding temperature was called the ignition temperature. The values found for hydrogen are given in Table 3 .

These observations served to confirm previous results, which indicated that a wire becomes more active after being heated in hydrogen and that its activity gradually declines when the wire is left unheated for a long time. New wires must be glowed to remove the film of grease or other inactive material covering the metal. No wire which had once been active was observed to require a temperature higher than $330^{\circ} \mathrm{C}$ to ignite hydrogen. The ignition temperature for carbon monoxide and for illuminating gas was found to be practically the same as that for hydrogen. $86062^{\circ}-19-3$ 
If any difference exists, the lower temperature is required for carbon monoxide. Methane behaves somewhat differently. Combustion first begins at a temperature of about $700^{\circ} \mathrm{C}$ and increases so gradually with increase of temperature that it is impossible to assign any definite ignition temperature.

TABLE 3.- "Ignition Temperatures" of Hydrogen at the Surface of Platinum Wires

\begin{tabular}{|c|c|c|}
\hline Diameter of wire & $\begin{array}{c}\text { Ignition } \\
\text { tempera- } \\
\text { ture }\end{array}$ & Remarks \\
\hline \multirow[t]{6}{*}{$0.097 \mathrm{~mm}$, sample C............ } & 174 & e \\
\hline & 175 & \\
\hline & 192 & Observed 17 hours after previous heating \\
\hline & 108 & Observed 1 minute after previous heating \\
\hline & 171 & \\
\hline & 170 & \\
\hline \multirow[t]{6}{*}{$0.053 \mathrm{~mm}$, sample B............ } & 175 & \\
\hline & 142 & \\
\hline & 165 & \\
\hline & 168 & \\
\hline & 170 & \\
\hline & 175 & \\
\hline \multirow{6}{*}{0.012 , sample A.... } & 730 & Wire not previously heated \\
\hline & 190 & \\
\hline & 191 & \\
\hline & 185 & \\
\hline & 265 & Observed 2 hours after previous heating \\
\hline & 157 & \\
\hline
\end{tabular}

Heat of Combustion. - The total amount of heat from combustion at the surface of a wire was determined in the manner described and illustrated under the heading "Method of study." The amount of heat from combustion per unit length of wire $\mathrm{C}$ for each per cent of gas entering the test bottle is plotted in Fig. 6. The data represented by the curve for hydrogen include the results of over roo observations upon seven concentrations of hydrogen in the gas mixture. The individual observations upon three concentrations are given in order to show the agreement of results. The heating effect upon the wire of the 8.2 per cent mixture falls off at temperatures above $1000^{\circ} \mathrm{C}$. This is no doubt caused by the fact that combustion takes place at some distance from the wire, and the supply of hydrogen to the surface of the wire is thereby reduced. It will be seen that the amount of carbon monoxide burned is almost independent of temperature, while the amount of methane burned increases rapidly with increase of temperature. 


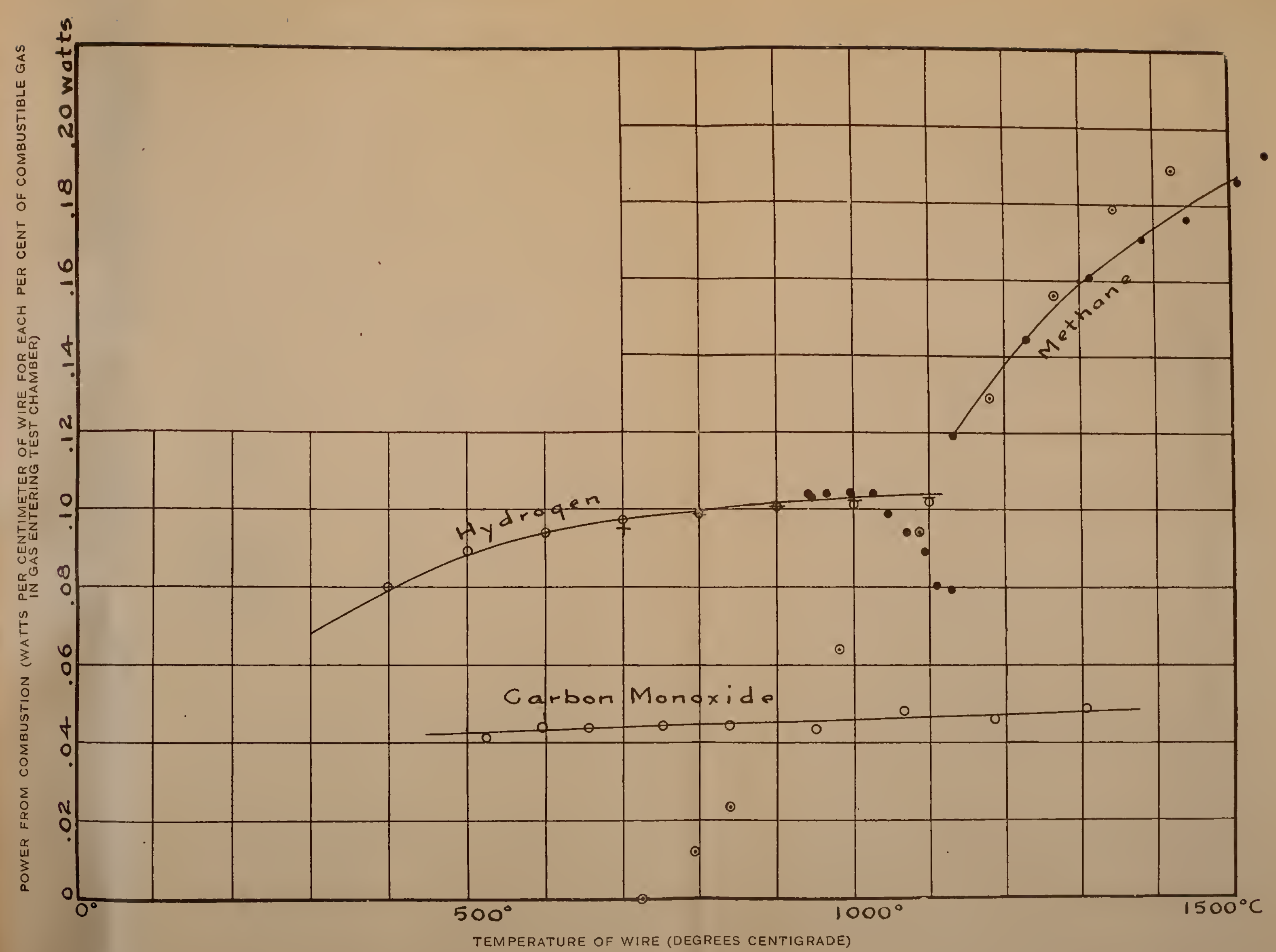

FIG. 6.-Power from combustion

Curves represent average for all concentrations of gas entering test chamber betwcen z and 6 per cent. Indivilual wiservations are represented as follows: Hydrogen, $O, 2.2$ ner cent;,+ 5.6 per s6062 $2^{\circ}-19$. (To face page 62 .) 
Fig. 7 shows the results of tests exactly similar to those shown in Fig. 6, except that different wires were used and that samples of gas drawn from a point about 2 centimeters below and to one side of the wire were analyzed and the percentage found by analysis was used in computing results instead of the percentage entering the bottle. It is probable that the results shown in Fig. 7 represent more closely the amount of gas which would be burned by an exposed wire in a large room than do those of Fig. 6. This latter figure may, however, better represent the performance of a detector partially inclosed to protect it from mechanical injury, excessive

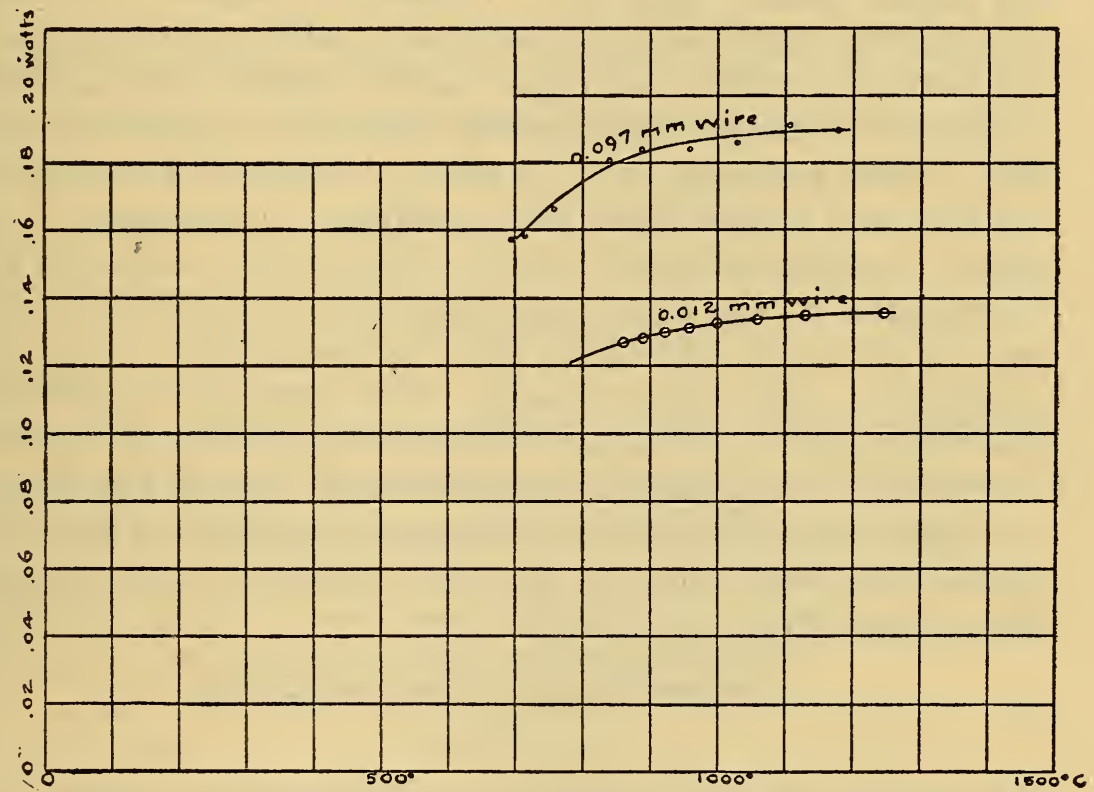

TEMPERATURE OF WIRE

FIG. 7.-Observed power from combustion at the surfaces of different wires

drafts, or to prevent the hot wires igniting the gas surrounding the detector.

The above experiments lead to the following conclusions:

I. The power from combustion depends upon the condition of the surface of the wire to some extent, but when heated to a suffciently high temperature the differences due to this cause are slight and the amount of power from combustion is reproducible.

2. The power from combustion is proportional to the amount of gas in the surrounding atmosphere until the composition of the mixture approaches the explosive limit. 
3. The power from combustion increases with the temperature of the wire, most rapidly in the case of methane.

4. Any observed differences in the power from combustion which could be ascribed to differences in the sizes of wires were of the same order of magnitude as the differences in total heat loss per second due to the same cause.

Temperature of Wires.-Since neither the heat loss in air nor the power from combustion varies rapidly with size of wire, it is to be expected that the temperature rise produced by combustion, which is a function of the ratio of the other two properties, will not depend greatly upon size. Indeed, the process of diffusion by which the combustible gas reaches the wire and the process of conduction by which most of the heat is removed are sometimes regarded as a single phenomenon. Convection plays the same part in both processes, and the effect of radiation from wires of the sizes and temperatures with which we are concerned is not great. A consideration of these facts leads to the conclusion that the temperature rise due to combustion must be practically independent of the diameter of the wire. A considerable number of experiments verify this conclusion. The temperature rise for the two wires $\mathrm{A}$ and $\mathrm{C}$, differing in diameter by a factor of 8 , showed a difference in temperature rise for each per cent of hydrogen of less than 2 per cent, and this difference is believed to have been due to the small amount of platinum black left when the silver was removed from the Wollaston wire.

\section{COMPENSATED BRIDGE INDICATOR}

(a) PRINCIPLES

A single wire whose resistance is measured by means of a Wheatstone bridge may be used to determine the amount of combustible gas in the atmosphere, but is not suitable for use in an automatic instrument, because its resistance is affected by changes in the current used tor heat the wire and in the temperature and movements of the atmosphere surrounding it.

In order to overcome this difficulty the compensated bridge indicator was developed. This instrument consists of an equal arm Wheatstone bridge in which one pair of opposite arms is active, while the other pair is inactive. Then if the resistances of all the arms are equally affected by changes in the conditions of operation, the balance of the bridge will not be affected by such changes. In the presence of a combustible gas, however, the combustion heats the active wires, increasing their resistance and 
unbalancing the bridge. The operation of a Wheatstone bridge of this kind can be deduced from Kirchhoff's laws, and shows how the unbalanced current, which causes the voltmeter to deflect, depends upon the resistance and sensitivity of the wires, the total current, the resistence of the voltmeter, etc.

If $r_{1}$ is the resistance of an active wire and $r_{2}$ that of an inactive wire, Kirchhoff's laws give for the galvanometer or voltmeter current

$$
i=\frac{I / 2\left(r_{1}-r_{2}\right) I^{\prime}}{r+I / 2\left(r_{1}+r_{2}\right)}
$$

where $I^{\prime}$ is the total current and $r$ is the voltmeter resistance. The resistances of the wires change with current and per cent of combustible gas in approximately the following manner:

Where-

$$
\begin{gathered}
\boldsymbol{r}_{1}=R\left(\mathrm{I}+S X+C_{1} \cdot \frac{I_{1}-\mathrm{I} / 2 I}{\mathrm{I} / 2 I}\right) \\
\boldsymbol{r}_{2}=R\left(\mathrm{I}+C_{2} \frac{I_{2}-\mathrm{I} / 2 I}{\mathrm{I} / 2 I}\right)
\end{gathered}
$$

$R$ is the resistance of one wire of the bridge when the normal operating current $I$ flows through the bridge as a whole, when no combustion is taking place, and when the bridge is balanced.

$S$ is the "sensitivity" of the active wires, defined as the proportional change in resistance with change in percentage of combustible gas $x$, so that $S$ is identical with $d R / R d x$.

$I_{1}$ and $I_{2}$ are the currents in the active and inactive wires, respectively.

$C_{1}$ and $C_{2}$ are the coefficients, respectively, for the active and inactive wire of proportional change of resistance with proportional change of current, i. e., $C$ is defined as $\frac{d R}{R}$ divided by $\frac{d I}{I}$.

Substituting these values in the equation for the voltmeter current and remembering that $I_{1}=1 / 2\left(I^{\prime}-i\right)$ and $I_{2}=1 / 2(I+i)$ one finds:

$$
i=\frac{I / 2 R I^{\prime}\left[S X+\left(C_{1}-C_{2}\right) \frac{\left(I^{\prime}-I\right)}{I}\right]}{r+R+I / 2 S R X+1 / 2\left(C_{1}+C_{2}\right) \frac{R I^{\prime}}{I}} .
$$

It is seen from this that one can consider the unbalanced voltage

$$
e=I / 2 R I^{\prime}\left[S X+\left(C_{1}-C_{2}\right) \frac{\left(I^{\prime}-I\right)}{I}\right]
$$


to act on the complete voltmeter circuit, which has a resistance equal to

$$
r+R+\frac{\left(C_{1}+C_{2}\right) I^{\prime} R}{2 I}+\frac{R S x}{2},
$$

where $\frac{\left(C_{1}+C_{2}\right) I^{\prime} R}{2 I}$ is an "apparent heating resistance," and $\frac{R S x}{2}$ is the increase in bridge resistance due to the presence of the gas.

When $C_{1}$ equals $C_{2}$ the unbalanced voltage is simply $\frac{R I^{\prime} S x}{2}$ and the resistance is $r+R+\frac{C I^{\prime} R}{I}+\frac{R S x}{2}$.

Usually $\frac{R S x}{2}$ and $\frac{C I^{\prime} R}{I}$ are only small parts of the resistance, so that the voltmeter current, and hence the reading, is proportional

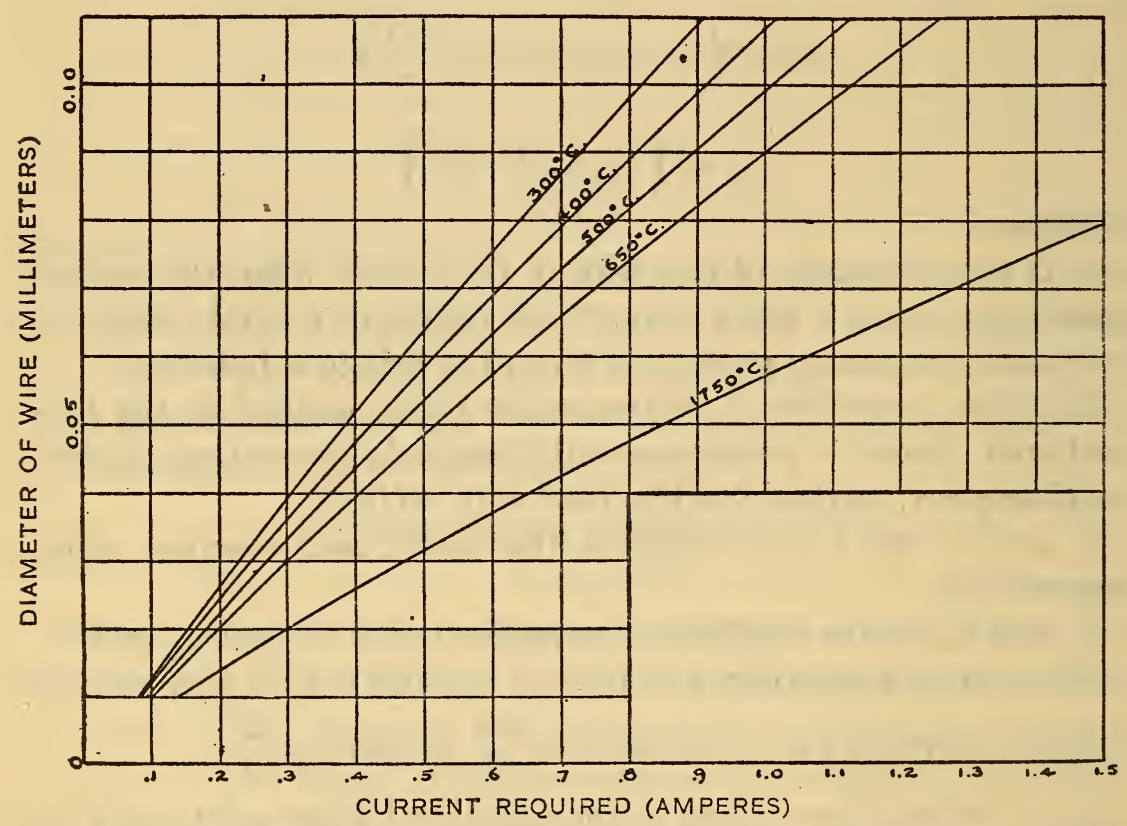

FIG. 8.-Current required to heat platinum wires of small diameter to various temperatures in air

to the sensitivity of the wires and the voltage across the bridge and inversely proportional to the resistance in the voltmeter circuit.

The sensitivity of a wire, unless very short and large, is practically independent of its length, but varies with the temperature, as shown by the curves of Fig. 9. These curves have been plotted from the direct observations on the resistance change in the various 
gases of platinum wires whose diameters varied from $0.012 \mathrm{~mm}$ to $0.226 \mathrm{~mm}$. There is some increase in sensitivity with diminution in the diameter of the wire, but the curves will give values sufficiently accurate for use in the design of compensated bridge indicators or any other devices using the resistance change as a measure of the amount of combustible gas in the atmosphere.

The sensitivity to other gases and vapors has not been accurately measured, but for illuminating gas, alcohol vapor, gasolene vapor, and some other compounds it is comparable with that for

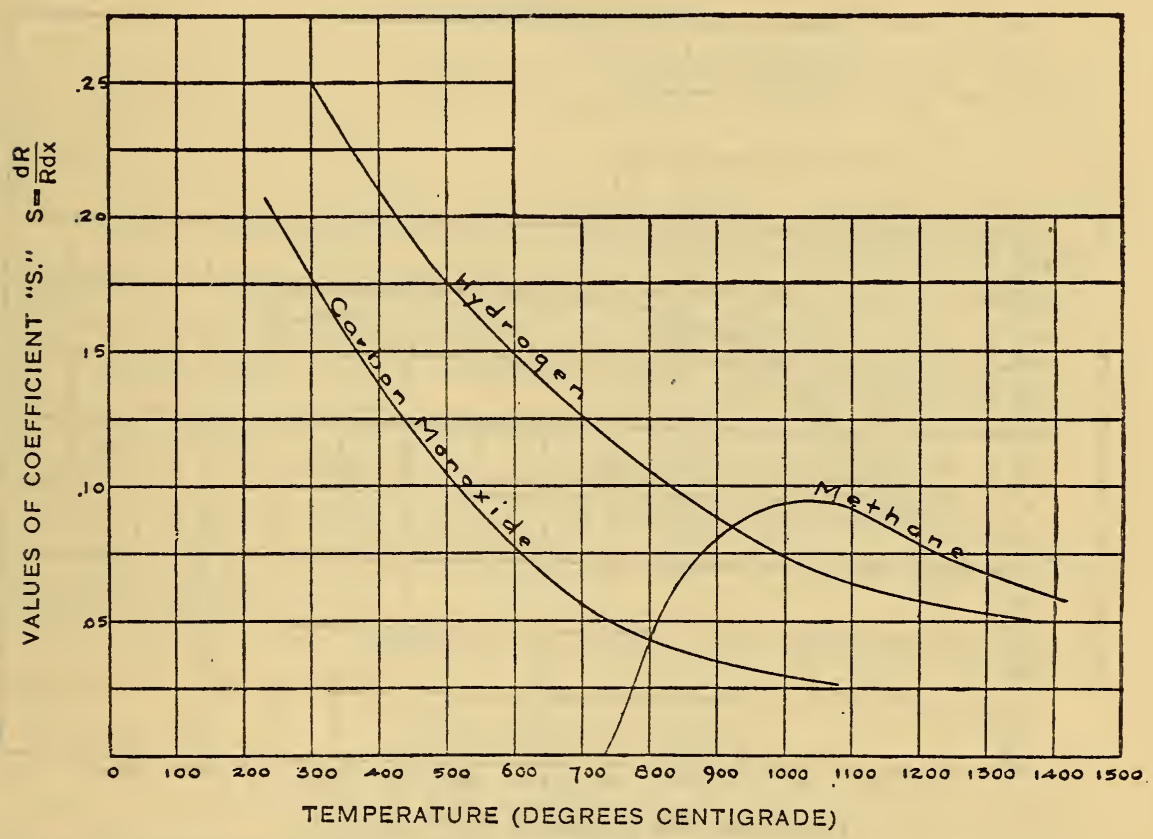

FIG. 9.-Coefficient of sensitivity of platinum wires

hydrogen. It is believed that there is ample sensitivity for the detection of any combustible mixtures before an explosive condition is reached.

The coefficient $C$ of proportional resistance change with change of current is practically independent of the length and diameter of the wire, unless this is very short and large, but varies with the temperature,'as shown by the curve in Fig. Io, which has been plotted from direct observations of the resistance change with change in current with the wires in air. This furnishes a means of determining the value of the coefficient $C$ which the inactive compensating wires must have if the bridge is to be compensated. The apparent heating resistance $C R$ can be readily calculated. 
Although it is possible to make $C_{1}$ and $C_{2}$ exactly equal by proper choice of active and inactive wires, in practice it is better to have a slight difference. When $C_{1}$ is not equal to $C_{2}$ the additional unbalanced voltage, i. e.,

$$
\frac{R I^{\prime}}{2} \frac{\left(C_{1}-C_{2}\right)\left(I^{\prime}-I\right)}{I}
$$

causes a deflection when the current is above or below the normal operating current. The magnitude of this effect is proportional

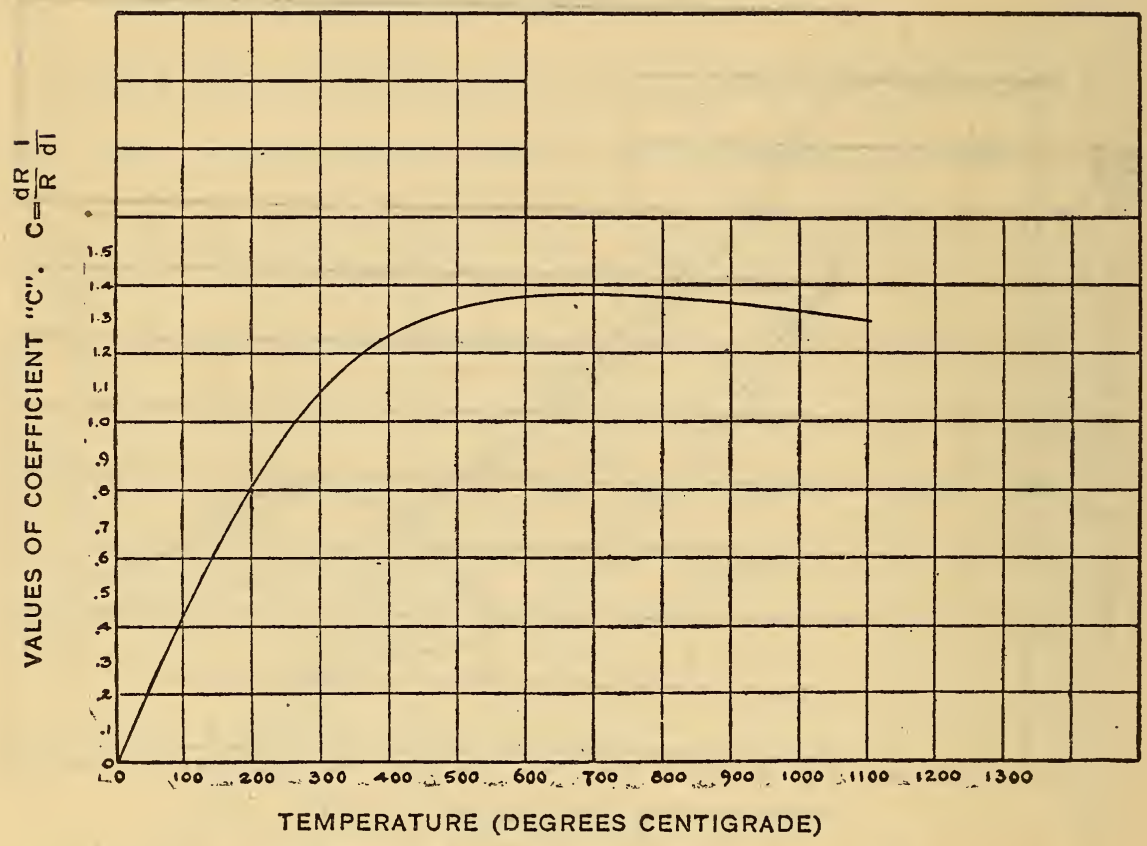

FIG. I0.-Coefficient of resistance change of small platinum wires with change of current at any temperature

to the difference in the coefficients $C_{1}$ and $C_{2}$. If instead of choosing a compensating wire whose coefficient is exactly equal to that of the active wire a wire is chosen which has a slightly different coefficient, it is possible to make the indications independent of (instead of proportional to) the total current for a given percentage reading. This will, however, only hold for this percentage, and the deflection for percentages above and below this will vary from the correct values in opposite directions with variation in the current. The variation in the readings due to change in current is, however, less than it would be with wires having the same coefficients. 
It can be easily shown that to produce absolute compensation at the percentage $x^{\prime}$ requires that

$$
C_{1}-C_{2}=S x^{\prime} \text {. }
$$

The coefficient of proportional resistance change with change of current is found to change with the temperature and therefore with the current in such a manner that it is usually possible to select as the value of the operating current one which will give absolute compensation in the percentage range of special interest.

\section{(b) DESIGN OF PARTS.}

In the design of a compensated bridge indicator to measure a particular range of percentages of a certain gas the best procedure is as follows:

I. Choose a convenient diameter $d$ of wire ( 0.025 to $0.1 \mathrm{~mm}$ ).

2. From the curves in Fig. 8 determine the current required to raise the wires to the following temperatures: For hydrogen, carbon monoxide, illuminating gas, and alcohol vapor, $500^{\circ} \mathrm{C}$; for gasolene vapor, $700^{\circ} \mathrm{C}$; and for methane and acetylene, $900^{\circ} \mathrm{C}$. The current given in the curves is one-half the operating current.

3. From the curves in Fig. 9 determine the sensitivity $S$.

4. From the curves in Fig. Io determine the coefficient $C$.

5. Choose a convenient length $L$ (not less than rooo times the diameter).

6. Compute the resistance $R$ from the following formula:

$$
R=1.25 \times 10^{-5} \frac{L}{D^{2}} Z
$$

where $Z$ is the ratio of the resistance of pure platinum at the operating temperature to the resistance at $0^{\circ} C$ obtained from Fig. 3 , and $L$ is the length and $D$ the diameter of the wire in centimeters.

7. Compute the unbalanced voltage $e$ from the maximum percentage to be indicated by using the formula

$$
e=\frac{R I S x}{2}
$$

8. Compute the bridge resistance $r$ by using formula

$$
r=R+C R+\frac{R S x}{2}
$$

9. Select a voltmeter which will give full scale deflection on the unbalanced voltage computed in 7 above when in series with a resistance greater than that computed in 8 above. 
The effect of variations in the design of the instrument may be determined in any particular case from the formulas and directions just given. The following general statements may, however, be useful:

Increasing the diameter of the detector wires diminishes the sensitiveness of the instrument and increases the operating current. It is consequently an advantage to use wires as small as is consistent with mechanical strength and the difficulty of covering with an inactive coating.

Increasing the operating temperature of the wires increases the current required and increases the sensitiveness of the instrument. This is limited by the temperature at which the inactive wire becomes active and by the stretching of the active wire in a high percentage of combustible gas. Decreasing the operating temperature decreases the current required and decreases the sensitiveness very rapidly, especially for methane.

When the bridge resistance is small compared with the voltmeter resistance, the sensitiveness increases nearly in proportion to the length of the bridge wires.

For compensating wires one may use any wires which continue inactive, which have the same resistance as the active wires, and which have nearly the same coefficients of change of resistance with change of current. As has already been stated, the compensating wires are most easily prepared by coating platinum with a substance which will render it inactive.

Gold, nickel, and glass have been used for this purpose, but the metal coatings were found to be less satisfactory than glass for the three following reasons:

I. The metal coatings are not permanent; volatilization or alloying or both take place slowly until the protective coating practically disappears. This may take several months of continuous service, but is sure to occur in the end. No such change has yet been observed with glass-covered wires.

2. The metal-plated wires are at the same temperature as the active wires and cause combustion if the temperature is raised sufficiently. With such difficultly combustible gases as methane and acetylene the temperature range within which the gas will burn at the surface of platinum and not at the surface of gold or nickel is rather small. The glass-covered wires, on the other hand, are not heated to such high temperatures in operation as are the active wires, and they remain inactive at higher temperatures than do the gold or nickel surfaces. 
3. The difference in coefficient $C$ between the glass-covered and the bare platinum wires enables us to choose an operating condition such that the indications of the instrument will be independent of temperature at the percentage of gas of most interest. Fig. I I shows the differences in behavior of a heavily glass-coated and a bare platinum wire when heated in air. It will be observed that practically perfect compensation for changes of current over the range 0.45 to 0.75 ampere can be obtained by making the compensating wires about 20 per cent longer than the active wires.

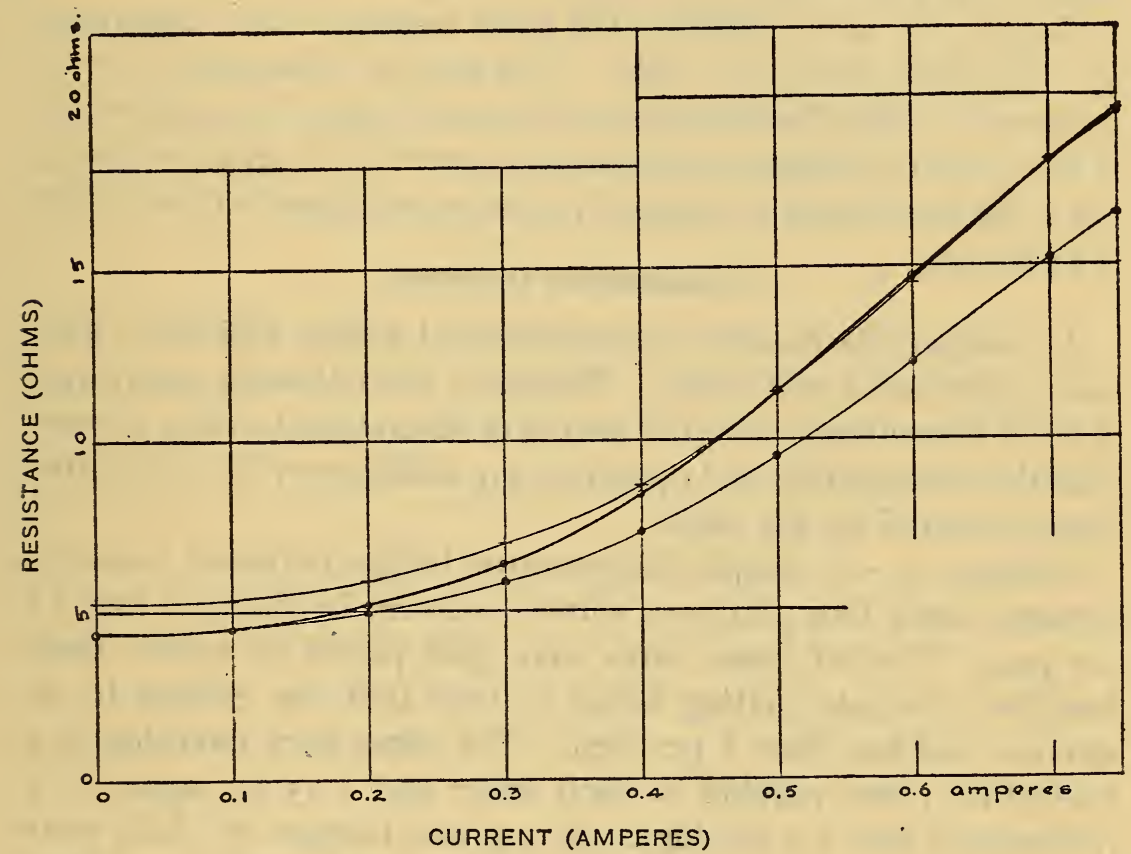

FIG. II.-Observed resistance in air of bare and glass-covered platinum wire

Upper curve, $9.5 \mathrm{~cm}$ glass-covered wire; middle (heavy) curve, $8 \mathrm{~cm}$ bare wire; lower curve, $8 \mathrm{cma}$ glasscovered wire.

For compensating the instrument to give readings independent of current in the presence of a considerable amount of combustible gas, the difference in length need not be so great as this.

If the compensated bridge indicator is to be used under conditions in which there is a possibility of the gas mixture reaching the explosive proportions, metal protective gauzes should be placed between the wires and the outside atmosphere. Double copper gauzes 24 meshes per $\mathrm{cm}$ ( 60 meshes per inch) have been found to be satisfactory even in hydrogen-air mixtures of maximum explosibility. When gauzes are used or when the wires are inclosed in any manner which obstructs the passage of the gas, the 
sensitiveness is thereby reduced somewhat. This need not be serious and seldom exceeds a reduction of 50 per cent.

The wires of the indicator must be so arranged as to be equally affected by motion of air caused by drafts or convection currents. The effect of drafts which may affect the wires unequally can be diminished sufficiently for most work by the use of properly placed baffle plates. Such baffle plates will not affect the sensitiveness of the instrument greatly. The combined effect of the baffle plates and the protective gauzes on the instrument specified in Section III is to diminish the total reading of the instrument by a little less than 50 per cent. This is of no consequence for the purpose for which the instrument is intended, since the sensitiveness of the type of voltmeter employed is so great that a series resistance has to be introduced to increase its range, expressed as percentage of hydrogen.

\section{(c) DESCRIPTION AND TESTS}

A considerable number of compensated bridge indicators have been constructed and tested. However, the following description of three instruments with the results of tests should suffice to show that the construction and operation are satisfactory for the limited period covered by the tests.

Indicator A.-A simple compensated bridge indicator was constructed using four platinum wires $0.0026 \mathrm{~cm}$ in diameter and 5.6 $\mathrm{cm}$ long. Two of these wires were gold plated to render them inactive, the gold plating being so thin that the change in resistance was less than I per cent. The wires were mounted in a horizontal plane parallel to each other and $1.25 \mathrm{~cm}$ apart in a rectangular case $2.5 \mathrm{~cm}$ high, the top and bottom of which were open, so that the wires were freely exposed to the surrounding atmosphere. A Weston miniature voltmeter having 3 and $I_{5}$ volt ranges, with resistances of 220 and I IOO ohms, respectively, was used as the indicating instrument.

By adjusting one wire the bridge was balanced. The detector bridge was then placed in a box supplied with a steady stream of air containing, in any experiment, a constant and known percentage of hydrogen. Fig. I 2 shows how the reading changes with change in the percentage of hydrogen in the air entering the box. It is observed that concentrations as low as 0.07 per cent give an indication, and that the proportionality between reading and percentage falls off only slightly at the higher percentages.

The effect upon the readings of protecting the instrument with double gauzes and baffle plates is also shown. The gauzes com- 
Bulletin Bureau of Standards, Vol. 15

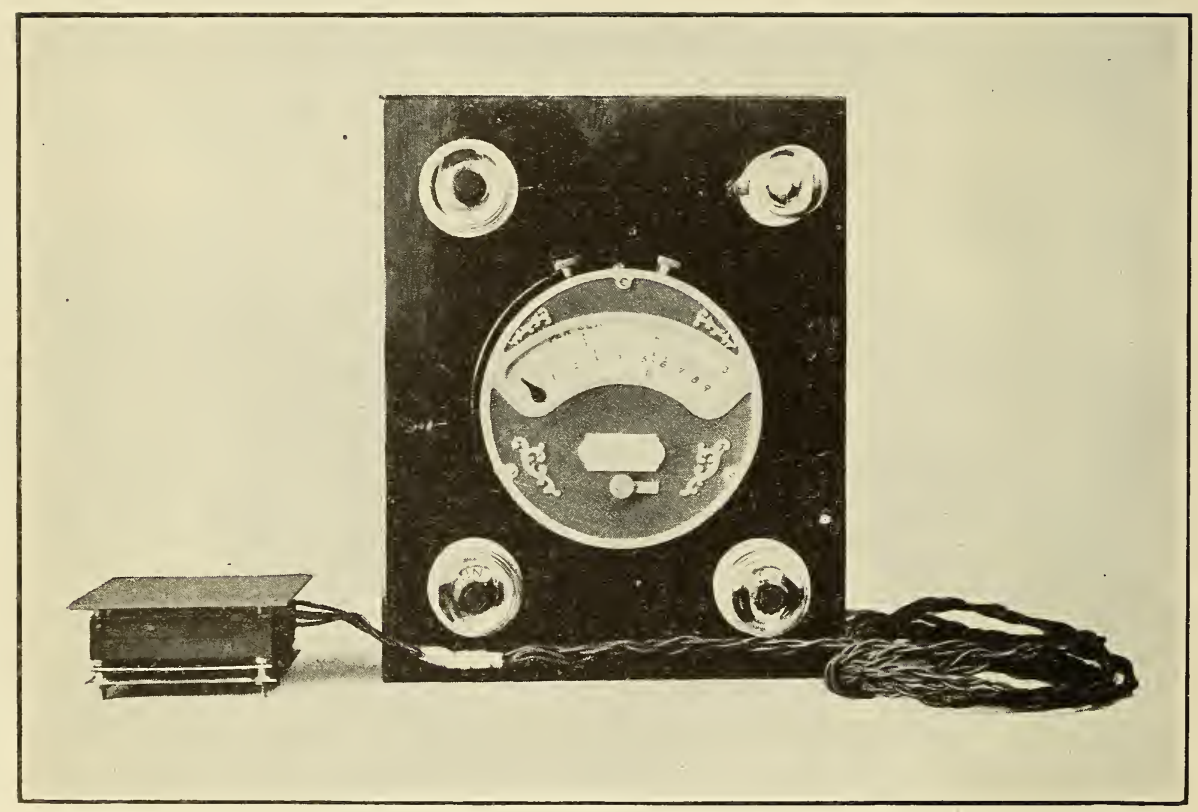

FIG. I3.-Indicator " $B$ " with connections 
pletely covered the openings at the top and bottom of the rectangular case and the baffle plates were parallel to these and $0.75 \mathrm{~cm}$ outside. The gauze was of iron wire $0.035 \mathrm{~cm}$ (o.014 inch) in diameter with II meshes per cm (28 meshes per inch).

The reading of this instrument for a given percentage was found to be practically proportional to the total current, which is in accordance with the theory of the compensated bridge in which the two coefficients, $C$, are equal.

This indicator was also tried out with carbon monoxide and with illuminating gas. The indications for any percentage of

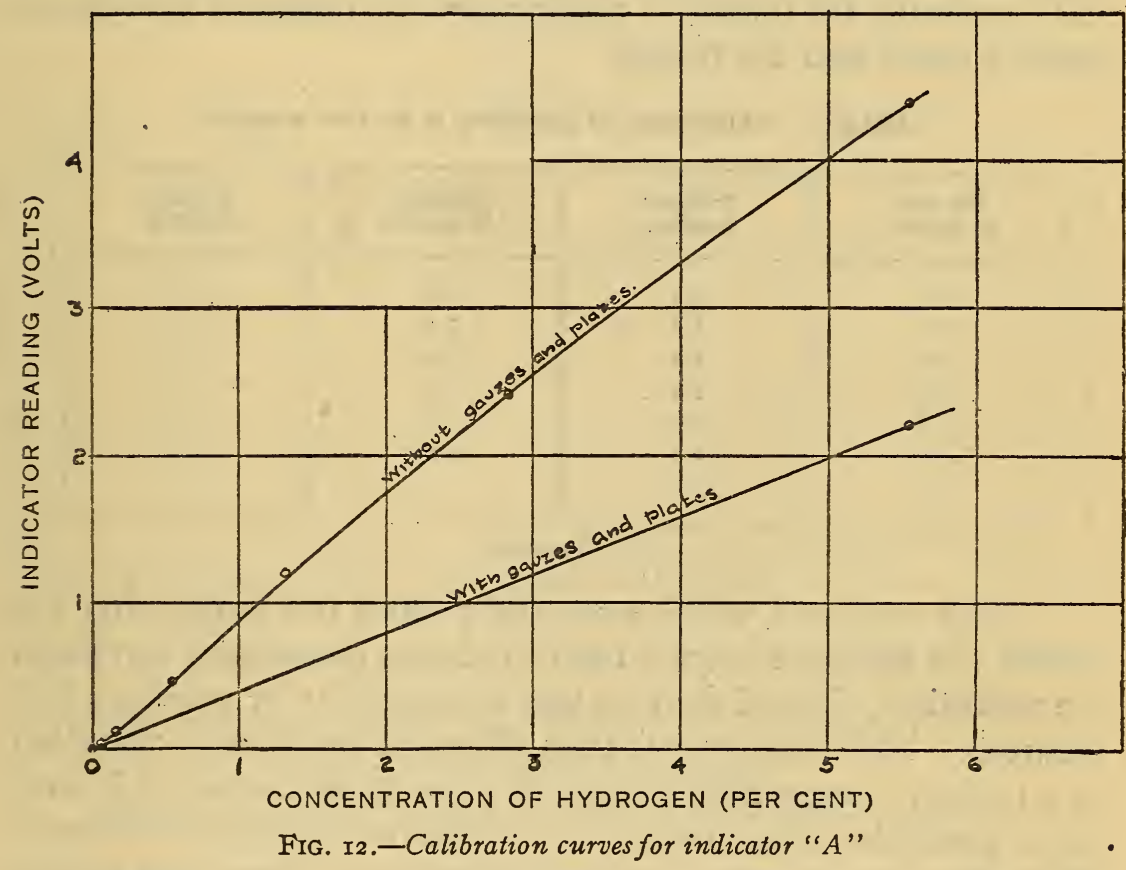

carbon monoxide was found to be about one-half that for the same percentage of hydrogen, while illuminating gas produced an indication slightly greater than that for the same percentage of hydrogen.

Indicator B.-Fig. $\mathrm{I} 3$ shows a complete compensated bridge indicator which was designed to indicate the percentage of hydrogen and to sound an alarm when this percentage had reached any predetermined value. The essential parts of this indicator are similar to those just described. The bridge was made of platinum wires, two of them gold plated, $0.053 \mathrm{~mm}$ in diameter and $6 \mathrm{~cm}$ long, supported in a hard-rubber case fitted with double gauzes and baffle plates. The indicating instrument is a Weston millivolt- 
meter, the scale of which was calibrated to read the percentage of hydrogen directly and to which a contact-making device had been attached. The lamp shows when the detector bridge current is flowing. The alarm bell is mounted on the back of the board and is operated through the contact-making device on the voltmeter from the main direct current supply.

The detector was calibrated and subjected to a large number and variety of tests during a period of two months. Table 4 shows some of the results of placing the detector bridge in a testing chamber supplied with a continuous stream of hydrogen-air mixture and comparing the indicator reading and the results of analysis of samples taken near the bridge.

TABLE 4.-Calibration of Indicator B by Gas Analysis

\begin{tabular}{|c|c|c|c|}
\hline $\begin{array}{c}\text { Per cent } \\
\text { by analysis }\end{array}$ & $\begin{array}{c}\text { Indicator } \\
\text { Reading }\end{array}$ & $\begin{array}{c}\text { Per cent } \\
\text { by analysis }\end{array}$ & $\begin{array}{c}\text { Indicator } \\
\text { Reading }\end{array}$ \\
\hline$(a)$ & 0.0 & 1.7 & 1.7 \\
1.1 & 1.0 & 2.0 & 2.0 \\
1.85 & 1.9 & 1.15 & 1.2 \\
1.85 & 1.8 & 2.1 & 2.1 \\
2.05 & 2.0 & 2.2 & 2.2 \\
2.5 & 2.5 & 2.2 & 2.2 \\
3.7 & 4.0 & & \\
\hline
\end{tabular}

$a$ No hydrogen.

The last two tests, which were made about two weeks after the others, the indicator having been in almost continuous service in the meantime, showed that no loss of sensitivity or accuracy had occurred. The detector was then placed in continuous operation in a battery compartment where it gave an indication of hydrogen in about the same quantity every time the battery was charged. After about two months continuous service, however, the indications of the instrument dropped off to about one-half the amount shown by analysis, and it was found that the change was due to the compensating wires having become active. The very thin gold plating (the change of resistance of the wire after plating indicated a coating less than 2 by ${ }^{10}{ }^{6} \mathrm{~mm}$ thick) was found to have disappeared by volatilization or alloying, although the fact that the instrument still showed one-half its original sensitivity was proof that some gold still remained. The ultimate activation of the gold-plated wires, which was the only observed cause of change in calibration in the earlier instruments, has been entirely overcome by the use of the glass-covered wires. 
Several indicators have been made using glass-covered wires and have, throughout all tests, given consistent results, and no change in calibration has been observed with any of them in which fair-sized wire was used and was not placed under tension.

The tests made on only a single instrument with glass-covered wires will be described. This instrument is designated as indicator $\mathrm{C}$.

Indicator C.-The bridge of indicator $\mathrm{C}$ was made up of four wires of commercial platinum $0.053 \mathrm{~mm}$ in diameter and $6 \mathrm{~cm}$

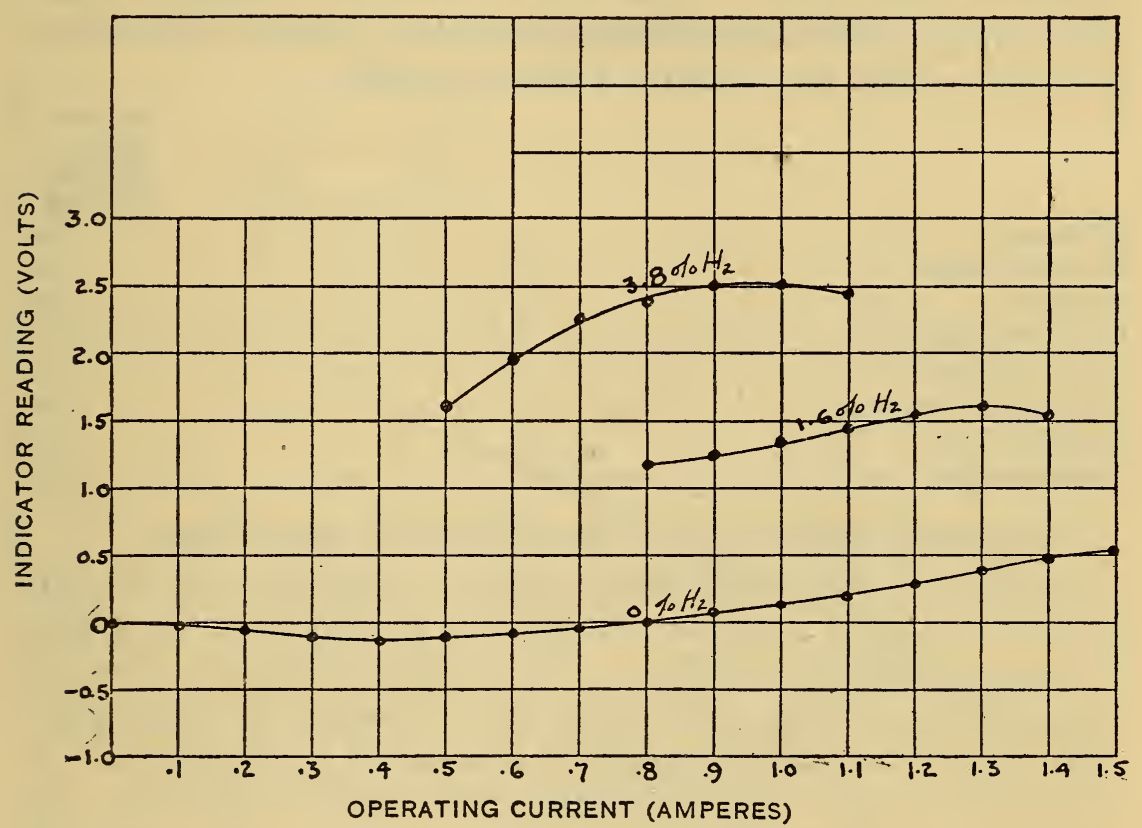

FIG. I4.-Operation of indicator " $C$ " with currents of different strengths

long, two of them coated with glass in the manner described on page 83 . The bridge was used with and without protective gauzes and baffle plates. It was found that the use of the protection cut down the reading for a given concentration of hydrogen to onehalf the value given by the unprotected instrument. Using the unprotected bridge, and measuring the unbalanced voltage with a Weston portable millivoltmeter of 9 ohms resistance in series with I9I ohms additional, the readings shown in Fig. I4 were obtained. The concentration of hydrogen was determined by analysis of samples of gas drawn from a point just beside the bridge frame. The figure shows how the unbalanced voltage changes with the percentage of hydrogen and with changes in the 
operating current. The effect of the difference in the coefficients $\mathrm{C}$ and the variation of this difference with percentage and currenti. e., with temperature-is clearly observable. The unbalanced voltage, calculated from the formulas and curves given under "Principles," for the normal operating current of I ampere, agreed with the observed value within 3 per cent.

Use for Detecting Other Gases.-The same indicator was used with certain necessary variations in the temperature of operation and resistance of voltmeter circuit, for testing for other gases. The voltmeter deflection for I per cent of each of the different gases was compared with the deflection caused by I per cent of hydrogen arbitrarily.called 1oo, with the following results:

Hydrogen .

Relative deflection caused by equal percent age of gas

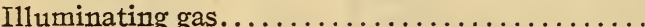

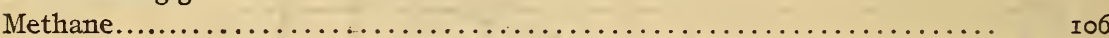

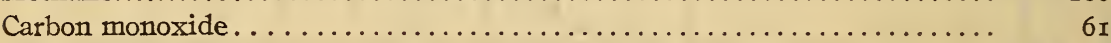

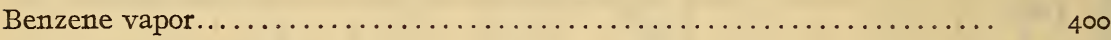

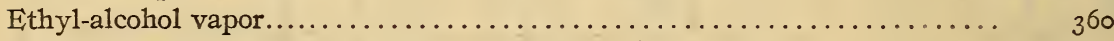

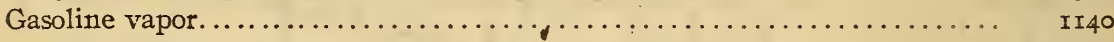

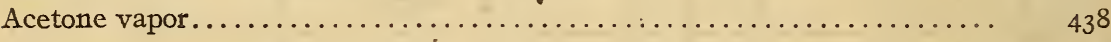

The general applicability of the detector is thus evident.

In some of these experiments explosive mixtures were formed inside the detector case, but the flame never penetrated the gauzes to the surrounding atmosphere. The reading of the detector when the explosive mixture was formed was of especial interest, since it represented the greatest deflection obtainable in the presence of the particular gas. Again referring the results to hydrogen, the relative deflections caused by the explosive mixtures were as follows:

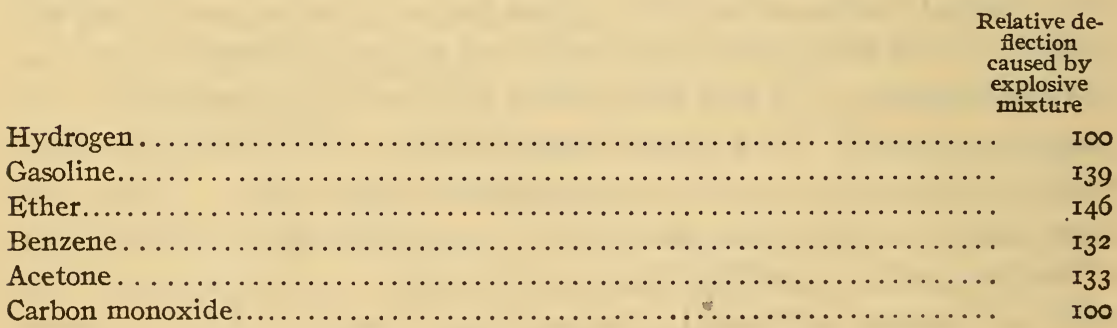

These results, while not of great accuracy, show that the indication given by the explosive mixture of a gas in air is of the same order of magnitude whatever the gas may be. 


\section{GLOWING-WIRE INDICATOR}

The temperature at which a platinum wire shows a visible glow, while depending somewhat upon the conditions of observation, can be judged quite accurately under any ordinary conditions of illumination. Six observations were made upon a $3 \mathrm{I} \mathrm{cm}$ length of wire $\mathrm{C}$ by the following method: The wire was stretched horizontally in an ordinarily well-lighted room, but in a position in which the light from the windows did not fall directly upon it. It was then heated by a current which was slowly increased until

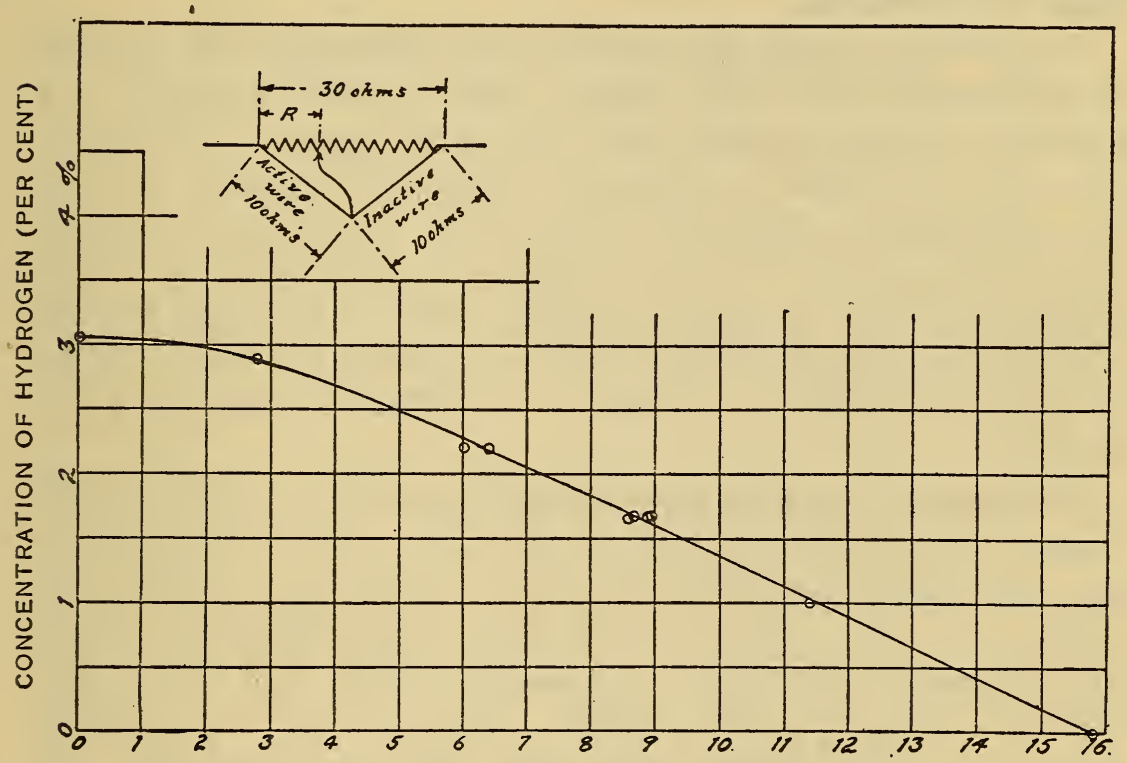

RESISTANCE "R" SHUNTING ACTIVE WIRE (OHMS)

FIG. I5.-Diagram of connections and curve showing performance of glowing-wire indicator

the reflected light was no longer noticed in comparison with the radiated light. The resistance was then measured and the temperature calculated, with the following results for the six observations: $675^{\circ}, 684^{\circ}, 684^{\circ}, 680^{\circ}, 688^{\circ}, 690^{\circ} \mathrm{C}$. The precision with which the temperature at the first visible glow can be determined is thus evident.

It has been shown by Lummer and Kurlbaum ${ }^{\circ}$ that, at this temperature a change of $I$ per cent in the absolute temperature causes a change of about 30 per cent in the light emitted. Taking data from Figs. 4, 7, and 1o, it is found that at this temperature I per cent change in current causes a change of about I.3 per cent 
in the absolute temperature, or 40 per cent in the light emitted; whereas the presence of one-tenth of I per cent of hydrogen in the atmosphere about the wire causes a temperature change of 2 per cent in the absolute temperature or 60 per cent in the light emitted. It is apparent from these facts that the absolute temperature can be easily determined from the luminosity of the wire to within 2 per cent. Consequently one should be able to determine the amount of hydrogen present in the atmosphere about the wire to a tenth of I per cent by observing the current required to make the wire glow.

An apparatus using this principle for determining the amount of combustible gas is very simply made, consisting merely of a platinum wire, an ammeter, and a source of current. The apparatus can be calibrated by observing the current required to make the wire glow in atmospheres containing various percentages of combustible gas. If a concentration of gas greater than that required to keep the wire at visibility without electrical heating is to be measured, the amount of air reaching the wire must be limited by inclosing in gauzes or by otherwise restricting the air flow.

The necessity for using an ammeter is eliminated in the portable glowing-wire indicator shown in Fig. 2I. An inactive wire is mounted beside the active wire and is used as aistandard for brightness. The I5-ohm rheostat shown determines the ratio of the currents in the active and inactive wires, and the Io-ohm rheostat varies the total current. Since the ratio of currents required to make the two wires glow with equal brightness will decrease with the percentage of gas present, the I5-ohm rheostat can be calibrated in terms of the percentage of gas.

The relation between the readings of a glowing-wire indicator having somewhat different electrical resistances than those above specified, with analyses of the gas taken from a point a few centimeters from the wire, together with a diagram of connections, are shown in Fig. I 5. It will be seen that the greatest deviation from the calibration curve of any single observation is only o.I per cent of hydrogen, while the average deviation is only a few hundredths of a per cent.

\section{BIMETALLIC DETECTOR}

The action of a bimetallic detector depends upon the temperature change in a bimetallic strip caused by temperature changes in a near-by wire. It would be difficult to predict the temperature 
change of a strip produced by a given temperature change of the wire, and even if this were known, the movement of the strip would be difficult to compute since it is a function of the length and of the thickness, coefficient of expansion, and elastic modulus of each of the metals of which the strip is composed. Fortunately, the use of an adjustable contact permits so wide a range of adjustment that it is unnecessary to design the instrument to give any predetermined deflection.

Fig. I 6 shows one of these instruments made at this Bureatr. The bimetallic strips used in it were made up from brass $0.23 \mathrm{~mm}$ thick and a nickel-steel alloy of the same thickness. The two bimetallic strips $a$ and $b$ are each attached at one end to an insulating support $c$ in such a position that the free ends of the strips will bend in the same direction (downward in the drawings) when heated. One of the strips, $b$, bears an insulated contact piece, $d$, which makes contact with the free end of $a$ when the free ends of the two strips are in a certain relative position. By means of perforated mica disks $e$ wires $f$ and $g$ are suspended a short distance below strips $a$ and $b$. One end of each wire is attached to the connecting piece $h$. Wire $f$ is a platinum wire $0.05 \mathrm{~mm}$ in diameter coated with glass, and $g$ is a piece of the same wire without coating. A copper wire $i$ connects the contact piece $d$ to a binding post and thence to one terminal of an electric bell $j$, the other terminal of which is connected to $b$. The screw $k$ serves to adjust the position of $b$, and thus the distance between the contact points on $a$ and $d$. As in the case of the other types of instruments, the hot wires are inclosed by gauzes, which permit circulation of air, but protect the instrument from mechanical injury, and serve to prevent the ignition of gas in the surrounding atmosphere.

When an electrical current is passed through the instrument, the two strips $a$ and $b$ are equally affected by heat from the wires; hence there is no relative movement of their free ends. But when a combustible gas is present, it burns at the surface of the wire $g$; the heat from combustion is transmitted to the adjacent strip $b$, which bends downward and closes the contact between $d$ and $a$. The wires $f$ and $g$, which have a rather high resistance, are then short-circuited through $j$, and the alarm rings.

This instrument has been tried out and found to work satisfactorily. It is easily adjusted to make contact in the presence of 0.2 per cent of hydrogen. With this adjustment it does not make contact at any current when no combustible gas is present. 
In order to test the relative sensitivity of the apparatus with different currents flowing, the detector was placed in a box having a volume of 0.2 cubic foot. A stream of air containing 2.5 per cent

\section{Z.}
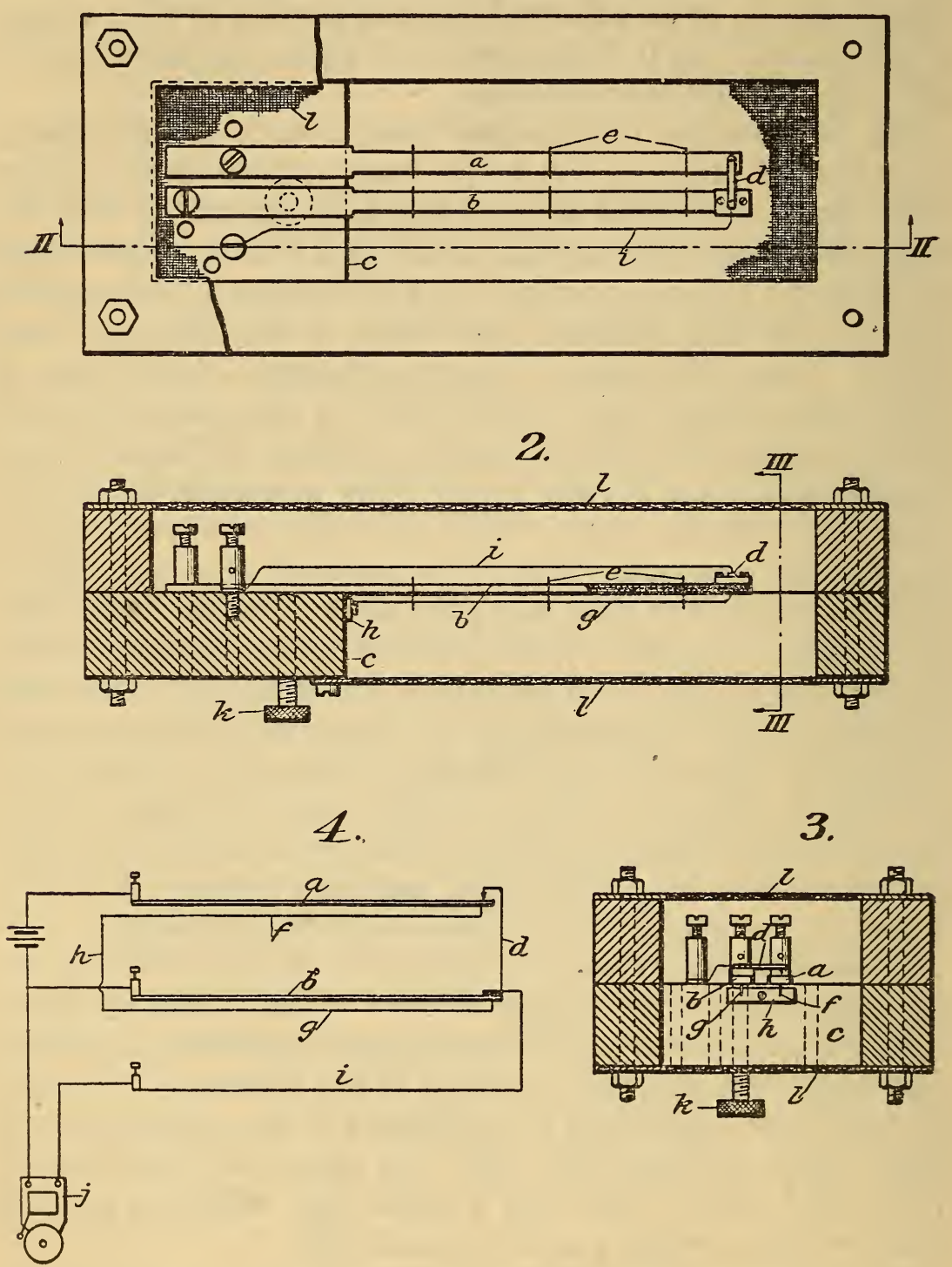

Fig. 16.-The bimetallic detector

of hydrogen was introduced into the box at the rate of o.I cubic foot per minute, and the time from starting the gas until the alarm rang was observed when currents of $0.4,0.5$, and 0.6 ampere 
were passed through the apparatus. With 0.4 ampere the times were 8 , Io, and I I seconds; with 0.5 ampere, from 9 to 12 seconds, averaging Io $1 / 2$ seconds, and with 0.6 ampere 13 to $\mathrm{I} 4$ seconds. These results indicate greater sensitivity when only a small current is used to operate the instrument, but there is little difference in this respect.

The sensitiveness of the instrument can be increased by increasing the length or reducing the thickness of the bimetallic strips.

\section{SPECIFICATIONS FOR THE CONSTRUCTION AND CALIBRATION OF INSTRUMENTS}

\section{COMPENSATED BRIDGE INDICATOR}

(a) CONSTRUCTION OF APPARATUS

The following specifications apply to the compensated bridge indicator believed to be best for general use. The form is one which has successfully met every test to which it has been subjected in the laboratories of the Bureau of Standards. The complete equipment (see Figs. I 3 and I 7 ) consists of as many detector bridges as are desired, a contact-making voltmeter and a cut-out switch for each detector, a main control switch, an indicating lamp, one ballast resistance, one alarm bell, and the cables connecting the detectors with the switchboard apparatus. The apparatus may, of course, be connected in a different manner than that shown in Fig. 20.

Detector Bridge. - The details of a detector bridge are shown to half size in Fig. 19. The four wires making up the bridge are fused to short pieces of copper wire of much larger diameter and the latter are soldered to four metal pieces $(a)$ screwed to the insulating piece $(b)$. This constitutes the detector element $(A)$. The base part $(B)$ consists of a metal plate $(c)$, the cover plate $(d)$ having a square opening covered with double gauzes and the insulating piece $(e)$. The parts are all fastened together and the four screws $(g)$ extend downward and serve to hold the detector element $(A)$ and the cover $(c)$ in place. Four rubber-covered wires are lead-soldered to the four metal pieces $(a)$ and pass out through one side of the insulating piece $(b)$. The lower part consists of the cover plate $(h)$ with double gauzes and the baffle plate (i). The parts $h$ and $i$ are similar to $d$ and $c$, respectively.

To assemble the detector, the detector element $(A)$ is slipped on the four projecting screws $(g)$ and fits nicely against the insulating piece $(e)$; the cover $(c)$ is then slipped on and the outside nuts placed on the screws $(g)$. The four wires are then connected to the cable. 


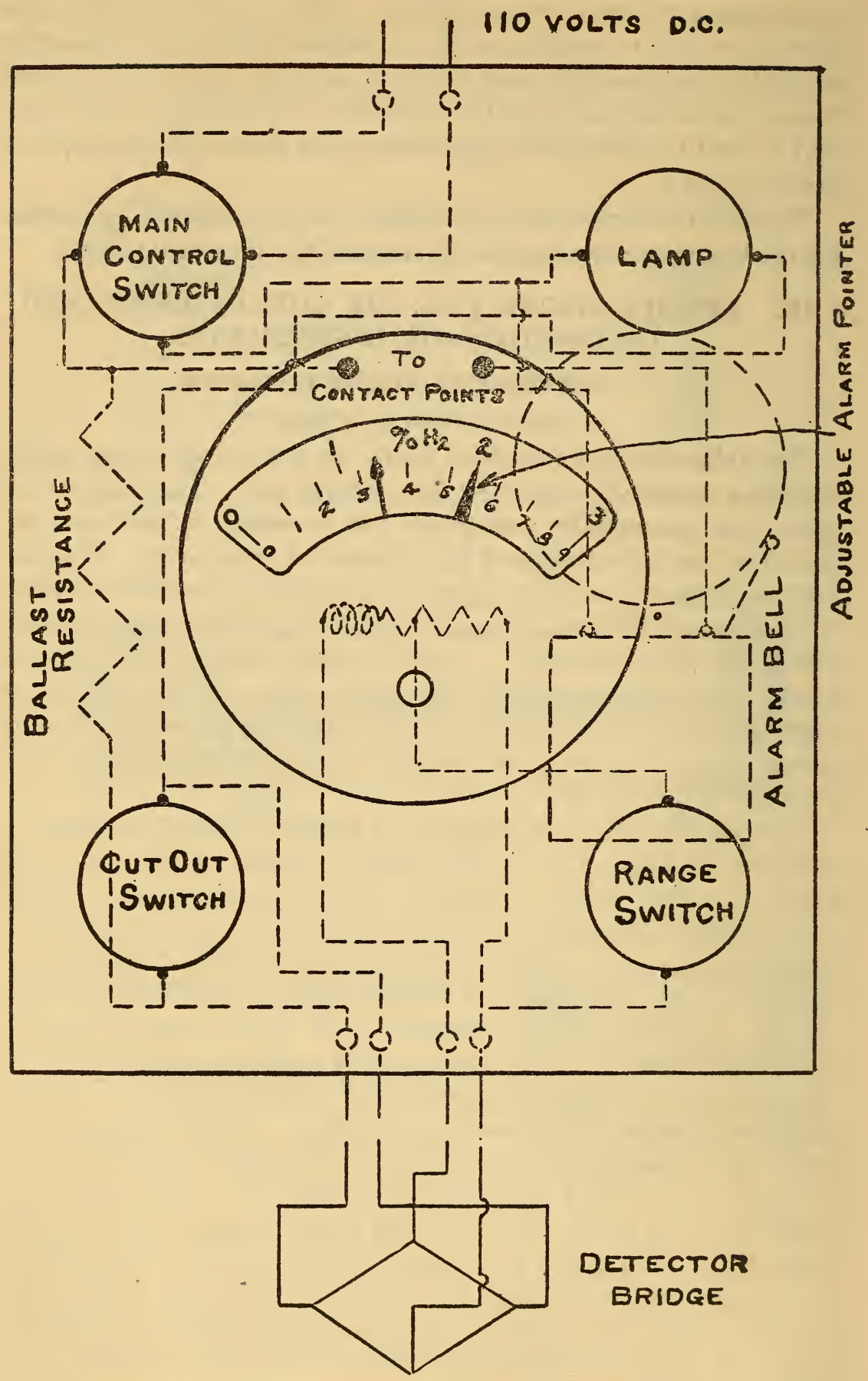

FIG. I7.-Diagram of connections of indicator " $A$ " 
The detector wires are to be of pure platinum $0.05 \mathrm{~mm}$ or 2 mils in diameter. Two of the wires (as marked) are to be covered with a thin coating of "sealing in" glass as described in the next section.

In fusing the glass-coated wires to the copper leads, the greatest care must be taken not to reduce the glass at the point of fusion. The copper must be melted in the reducing flame a few millimeters from the glass-coated wire, the two ends brought quickly together, and immediately removed from the flame. The wires should be straight when soldered into place.

When intended for use in battery compartments, the other metal parts of the detector, including the gauzes, are to be lead-

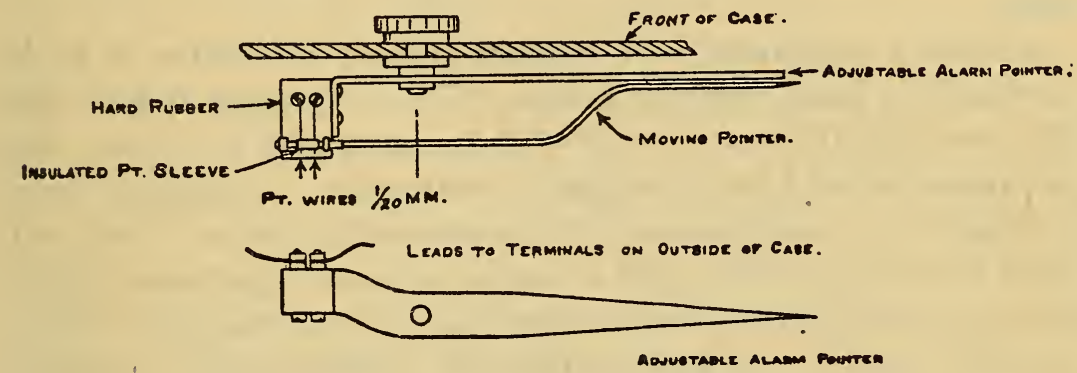

FIG. I8. -Contact-making arrangement for voltmeter used with indicator " $A$ "

coated in order to protect against corrosion by sulphuric-acid fumes.

The insulating pieces $(b)$ and $(e)$ are to be of hard rubber or Bakelite or any material known to give good service under the conditions of use of the detector.

Preparation of Glass-coated Wire.-A platinum wire is most quickly coated by melting a bead of sealing-in glass in the oxidizing flame of a fine-tipped blowpipe and allowing it to flow along the wire three or four times. The coating so formed should be quite smooth and not thicker than the diameter of the wire.

A better method is as follows: Make a hole twice the diameter of the wire or larger through a piece of platinum foil, thread one end of the wire through the hole from above, lay a small piece of sealing-in glass on the foil over the hole, heat with the tip of the oxidizing flame of the blowpipe until the glass is melted, and then draw the wire slowly through the melted glass and the hole in the strip. The wire comes out with a rather thick coating of glass, which incloses air between the glass and the platinum at many points and does not adhere very well. Now make a smaller hole through the strip about I.5 times the diameter of the wire. Thread the end of the wire through, heat, and draw as before, but 
without adding any more glass. This second operation removes most of the air from the glass and makes the coating adhere much better. Finally anneal the coating by running the wire slowly through the very tip of a blowpipe flame, even beyond the point at which the flame is visible. The wire should now be difficult to distinguish from the uncoated wire without the aid of a magnifying glass. The coating should adhere perfectly, even when the wire is bent through a rather short radius. Sealing-in glass must never be heated except in a strongly oxidizing flame, since it contains lead which is easily reduced to the metallic form and will alloy with the platinum. Even a very small amount of lead will change the properties of the wire in such a way as to make it useless.

Indicating Instrument.-A contact-making voltmeter is to be provided for each detector bridge. This voltmeter should give full scale deflection on 0.5 volt when in series with 25 ohms. The instrument should be of rugged construction, capable of being. mounted on a switchboard at the observing point. The voltmeter is to be provided with a contact-making attachment which closes an independent circuit when the pointer reaches a certain position, fixed by an extra adjustable pointer, which indicates the percentage at which the alarm is sounded. The contactmaking attachment shown in Fig. i 8 could be attached to a standard instrument if desired.

Accessory Apparatus. -The indicating and control apparatus for all the detectors is to be mounted on a switchboard. On the front of the board are one main switch, one indicating lamp, the contact-making voltmeters, and one cut-out switch for each of the latter. The ballast resistance and the alarm bell can be placed on the back of the switchboard.

The indicating lamp serves to show when the detectors are in operation. A 6-volt, lo-watt tungsten lamp is suitable for this purpose.

The ballast resistance should be made similar to any of the reliable resistance units in common use. The total resistance is to be determined by the number of indicators and the voltage of the supply circuit, and should be such that I ampere will flow through the circuit when all the detectors, the indicating lamp, and the ballast resistance are connected in series.

The switches are to be capable of handling I ampere at I Io volts under the conditions of use. Ordinary snap switches will usually serve the purpose. 


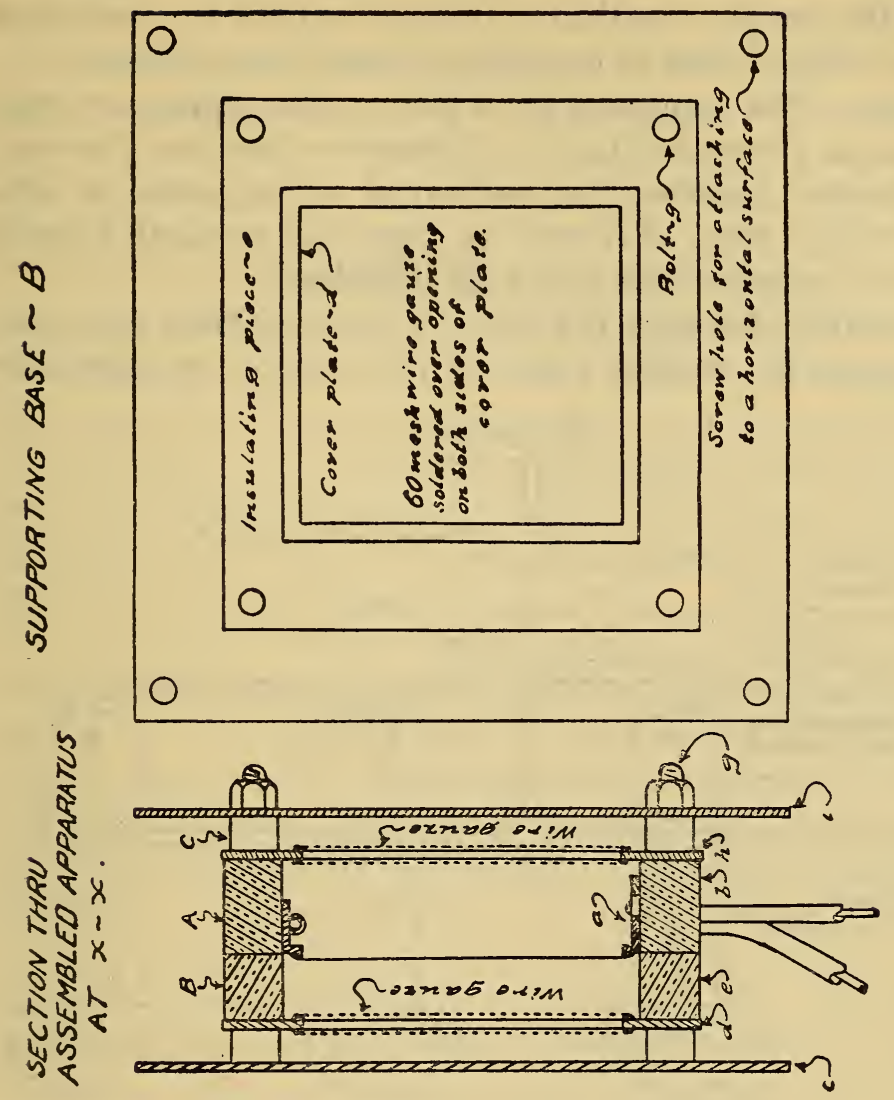

ปั.

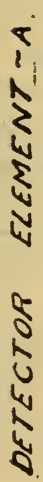
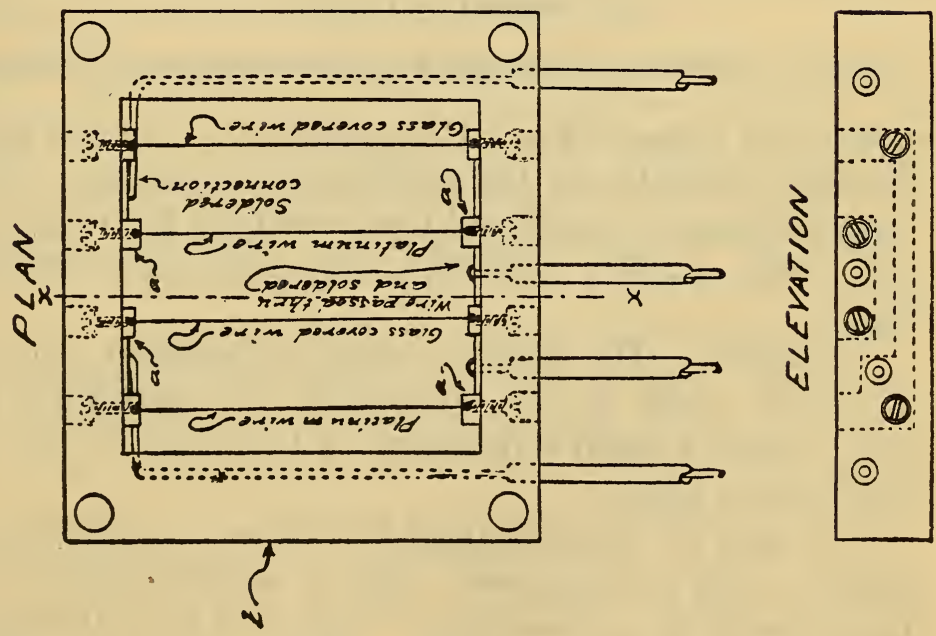
The alarm bell can be of any approved type, operating at the voltage of the supply circuit, or a relay may be connected in place of the bell and used to operate any mechanism desired.

Connections. - The apparatus for a four-station equipment may be connected as shown in Fig. 20. If more or less than four stations are installed together, the method of wiring would be similar. The bridges may, of course, be connected in parallel and a separate alarm may be used with each if desired.

The connections between the parts of the apparatus are made with conductors not smaller than $0.8 \mathrm{~mm}$ (or No. 20 American

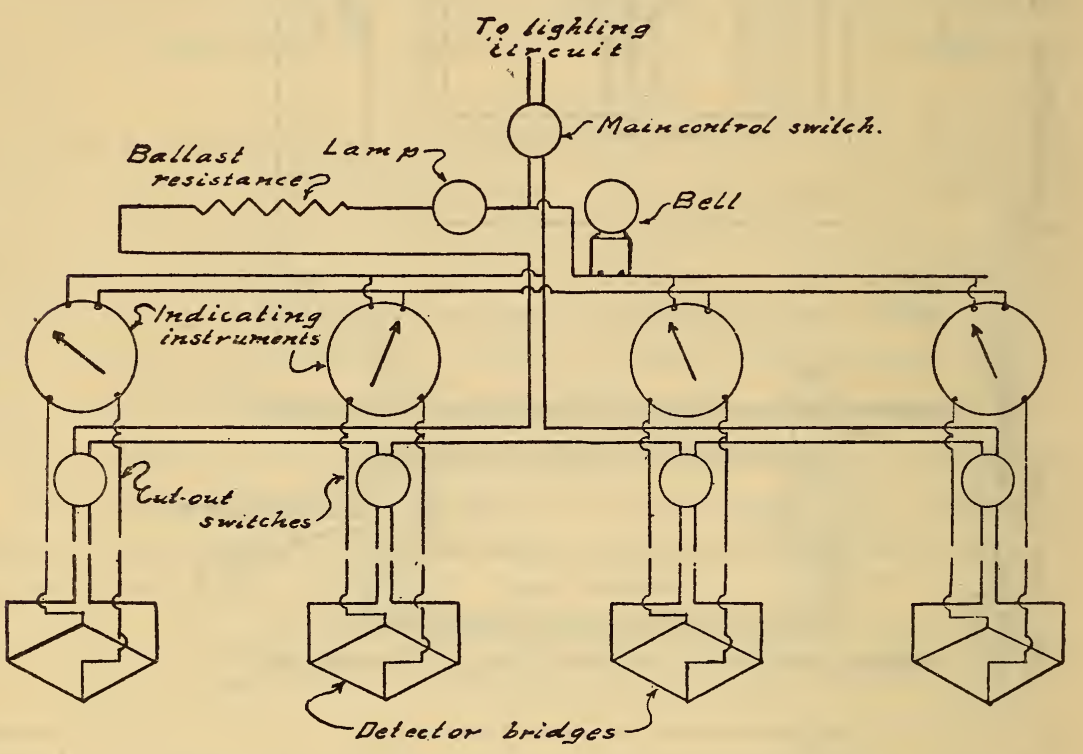

FIG. 20.-Diameter of connections for 4-station installation of bridge indicators

wire gage) copper wire. A four-conductor cable is used to connect each detector to the switchboard apparatus. The connections between the cable and the wires from the detector must be well made, suitably insulated, and protected from mechanical injury.

Calibration.-The detector bridge is balanced for a current of I ampere when in air containing no combustible gas. This may require a slight adjustment of the length of one or more of the detector wires.

The scale of the indicating instrument is calibrated by comparison with gas analyses. This is accomplished by operating the detector in a chamber of convenient size, through which a stream of air containing a constant percentage of combustible gas 
is passed at a constant rate until the reading of the indicator is constant. A sample of air is then drawn from a point near the detector case and analyzed by any reliable method. Since the detector reading is very nearly proportional to the amount of gas present, it is often sufficient to determine one point in the scale, and it will never be necessary to determine more than two or three points.

If the instrument is to be used only to indicate danger from explosion, the following method of calibration is easy and should be sufficiently accurate: Divide the scale of the indicating instrument into equal parts, reading from 0 to the explosive limit of the gas, place the detector in an atmosphere containing a known percentage of the gas equal to about three-fourths the explosive percentage, and adjust the resistance in series with the voltmeter until the reading is correct.

A continuous stream of gas mixture of known and uniform composition can be obtained by the use of geared meters, as shown in Fig. 2. To use this method successfully, it is best to have meters, one of which passes only about one-tenth the volume of gas per revolution that is passed by the other. The gas pressure on the meter passing the smaller volume of gas should be governed very accurately (within a few millimeters of water pressure) and the governor should pass a considerable volume of gas without any appreciable change in pressure. The connections from the meters through the mixing and testing chambers to the outlet should be large enough so that there will be no considerable back pressure upon the meters at the rate of flow used.

Operation. - When connected up as directed, it is only necessary to close the main switch to put the indicators in operation. As long as the indicator lamp is lighted and the bridges are balanced there is no probability that anything is wrong with the instruments. If the indicator lamp goes out, the cut-out switch for each instrument should be closed in turn. If the lamp lights up, the bridge then "cut out" is at fault and should be repaired, the other instruments remaining in service until this is accomplished. If, for any reason, it is suspected that oil or other impurity may have reached the active wires and rendered them inactive, they should be heated to a high temperature for a minute or two by increasing the current through the instruments to I.5 amperes. This current will not injure the detector and will remove any probable impurity which would render the wires inactive. When the bridge is first used, the wires must always be "glowed" in this manner. 


\section{GLOWING-WIRE INDICATOR}

Fig. 2 I shows the details of construction and a diagram of connections for a portable glowing-wire indicator of the form believed to be most suitable for general use. The following specifications apply to this instrument:

Wires.-The active and inactive wires are to be of pure platinum $0.05 \mathrm{~mm}$ ( $2 \mathrm{mils}$ ) in diameter and $2 \mathrm{~cm}$ long. One wire is made inactive by coating with "sealing-in" glass.

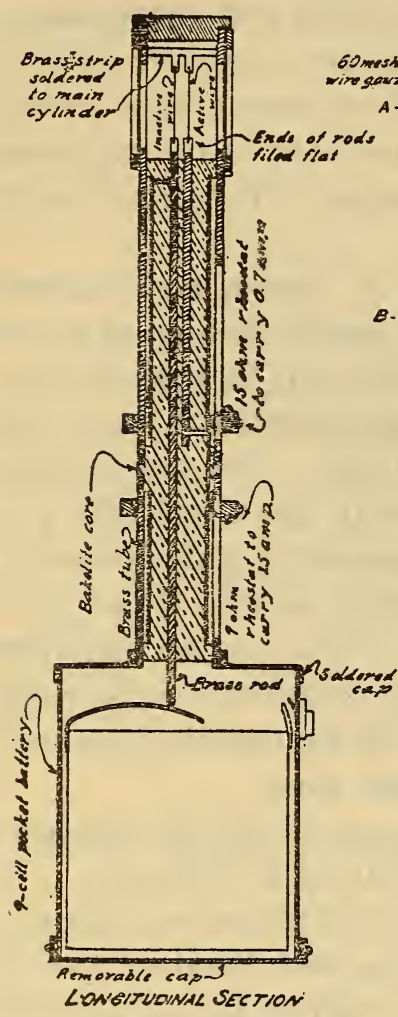

FIG. 21.-Portable glowing-wire indicator

Cap.-A cylindrical cap covered with double protective gauzes with 25 meshes per $\mathrm{cm}$ or 60 meshes per inch and containing a glass or mica observing window is to be provided as shown. The portion of the cap opposite the window is to be blackened to afford a dark background for observing the wires. The cap is to be held in position by the end plug, which can be removed to allow access to the wires.

Rheostats. - The rheostats are to be made by winding resistance wire of constantan or other equally good resistance material on the 
insulating core. Bakelite is a suitable material for the core. The sliding contacts must make good electrical connections between the rheostat wires and the outside brass tube.

Battery. -The battery should be capable of furnishing, at some position of the series rheostat, 0.9 ampere total current. From five to nine small cells, such as are used with pocket flash lights, should be satisfactory. Provision should be made for readily opening the battery case for renewing the battery.

Calibration.-The portable glowing-wire indicator should be calibrated in the following manner:

I. With the indicator in a gas-free atmosphere and shaded from any very bright light, adjust the two rheostats so that the two wires are equally bright. Mark the position of the slide of the I 5-ohm rheostat as o.o. In making this and all other settings, the brightness at which the most consistent settings can be made should be used. This will be when the radiated light from the wires is just distinctly visible.

2. With the indicator in atmospheres containing known percentages of the gas to be tested for, adjust the positions of the rheostats until both wires show the same brightness as before. Mark the positions of the slide on the 15 -ohm rheostat with the known percentage of gas. Unless great accuracy is desired, it will be unneccessary to determine more than three points on the scale. One of these is the position corresponding to no combustible gas present; one the position and percentage corresponding to no current through the active wire. The concentration for the third point should be equal to about 80 per cent of that required to keep the active wire glowing without electrical heat.

3. A scale should be marked on the brass tube, using the observed positions as reference marks and making the divisions between reference marks equal.

\section{BIMETALLIC DETECTOR}

Specifications are given below for a bimetallic detector believed to be suitable for operating an alarm at small percentages of all combustible gases. Fig. I 6 shows details of construction and a diagram of connections.

Wires.-The active and inactive wires are to be of pure platinum $0.05 \mathrm{~mm}$ ( 2 mils) in diameter, and about $15 \mathrm{~cm}$ long. The one wire is to be rendered inactive by means of a thin coating of "sealing-in" glass. The wires are to be supported I mm below 
the bimetallic strips by means of small perforated mica pieces spaced about $2.5 \mathrm{~cm}$ apart.

A small flexible wire is to be provided to make connection between the insulated contact block mounted at the end of one strip and the binding screw to which one terminal of the alarm is to be connected.

Bimetallic Strips.-The length and width of the bimetallic strips should be as shown in the figure. The thickness depends upon the material used, which should be such that the end of a piece $10 \mathrm{~cm}$ long will move $5 \mathrm{~mm}$ when the temperature of the strip is changed $50^{\circ} \mathrm{C}$. A bimetallic strip made from brass 0.25 $\mathrm{mm}$ thick firmly fastened to a strip of a nickel-steel alloy 0.25 mm thick operated satisfactorily.

Other Details.-An adjusting screw is to be provided equivalent to the form shown, for varying the distance between the contacting points in order to vary the percentage at which the alarm will operate.

A case is to be provided with openings covered with double gauzes of 25 meshes per $\mathrm{cm}$ ( 60 meshes per inch).

The detector is to be so arranged that electrical connections to the source of current and to the alarm can be readily made.

Calibration.-The operating current is to be 0.5 ampere if hydrogen, carbon monoxide, illuminating gas, or the vapor of most organic liquids is to be detected, but 0.7 ampere if methane is to be detected.

The screw should be adjusted so that contact is not made when the normal operating current is flowing and no combustible gas is present, but so that it just operates when the device is placed in an atmosphere containing the percentage of the gas which it is desired to detect.

Washington, April i8, I9I8. 